\title{
Catalytic amide formation from non-activated carboxylic acids and amines.
}

\author{
Helena Lundberg ${ }^{a}$, Fredrik Tinnis ${ }^{\mathrm{a}}$, Nicklas Selander ${ }^{* a}$ and Hans Adolfsson $* a$ \\ Received (in $X X X, X X X) X$ th $X X X X X X X X X 20 X X$, Accepted Xth $X X X X X X X X X 20 X X$ \\ DOI: 10.1039/b000000x
}

The amide functionality is found in a wide variety of biological and synthetic structures such as proteins, polymers, pesticides and pharmaceuticals. Due to the fact that synthetic amides are still mainly produced by the aid of coupling reagents with poor atom-economy, the direct catalytic formation of amides from carboxylic acids and amines has become a field of emerging importance. A general, efficient and 10 selective catalytic method for this transformation would meet well with the increasing criterias for green chemistry. This review covers catalytic and synthetically relevant methods for direct condensation of carboxylic acids and amines. A comprehensive overview of homogeneous and heterogeneous catalytic methods is presented, covering biocatalysis, Lewis acid catalysts based on boron and metals as well an assortment of other types of catalysts.

\section{1. Introduction}

The amide functionality is one of the most fundamental chemical building blocks found in Nature. It constitutes the backbone of the biologically crucial proteins, and it is present in a vast number of synthetic structures. For example, the amide bond is found in 20 up to $25 \%$ of all pharmaceuticals on the market, ${ }^{1}$ and it was present in $2 / 3$ of drug candidates which were surveyed by three leading pharmaceutical companies in $2006 .{ }^{2}$ It has been estimated that $16 \%$ of all reactions involved in the synthesis of modern pharmaceuticals was the acylation of an amine, which makes it 25 the most commonly performed reaction in this field. ${ }^{3}$ Polymers based on the amide linkage are of importance in a wide range of applications, from everyday materials such as nylons, to more advanced uses in drug delivery systems, adhesives and wound healing. ${ }^{4}$ In addition, the amide bond is commonly found as a key 30 structural element in agrochemicals and in products from the fine chemicals industry.

Formally, the amide bond is formed through the condensation of a carboxylic acid and an amine with the release of one 35 equivalent of water. This reaction has been considered challenging due to the competing acid-base reaction, which occurs when the amine and the carboxylic acid are mixed. Although the amide bond can be formed from the corresponding ammonium carboxylate salt upon heating, this reaction has 40 generally been considered to be of limited preparative value. ${ }^{5}$ Furthermore, the high activation barrier for the direct coupling of a carboxylic acid and an amine can only be overcome using forcing reaction conditions. ${ }^{6}$ In order to circumvent these problems, the amide bond is usually formed via an activated 45 carboxylic acid. The carboxylic activation is usually taking place with the aid of a coupling reagent, ${ }^{7}$ or alternatively by turning the carboxylic acid into the corresponding acid chloride (the Schotten-Baumann reaction). The use of coupling reagents usually results in mild reaction conditions and good yields, but 50 requires stoichiometric amounts of the reagent. Hence, at least one equivalent of waste is generated per product molecule formed, leading to an overall low atom economy. The removal of this waste from the reaction mixture is also a tedious and expensive process in addition to the cost and toxicity of the 55 coupling reagent itself. Due to these issues, as well as the importance of the amide bond in the pharmaceutical industry, a catalytic and waste-free production of amides was voted a highlighted area of research by the American Chemical Society's (ACS) Green Chemistry Institute (GCI) Pharmaceutical ${ }_{60}$ Roundtable (PR) in $2005 .{ }^{8}$

Many catalytic methods for the formation of amides have been developed, utilising starting materials such as alcohols, aldehydes, nitriles and aryl halides. ${ }^{9}$ However, relatively few ${ }_{65}$ protocols are known where carboxylic acids are used as starting materials, even though this catalytic transformation could easily be envisioned to be highly valuable in e.g. peptide synthesis. In recent time, the direct catalytic amidation of non-activated carboxylic acids has attracted more attention, with an increasing 70 number of groups focusing on this area of research. Although several reviews cover parts of the material presented herein, ${ }^{10}$ there is to the best of our knowledge none which compiles all types of catalytic methods for direct amidation. Thus, the aim of this review is to provide an easily accessible and comprehensive 75 overview of synthetically relevant literature on all types of catalysts for direct amidation, ranging from biocatalysis, Lewis acid catalysts based on boron reagents and different metal complexes, as well as other catalyst types. Both homogeneous and heterogeneous catalytic protocols are included, and the scope 
and limitations of the different systems are discussed. To date, most catalytic protocols for direct amidation require elevated reaction temperatures and water scavengers and/or suffer from a limited substrate scope. We hope that this review will inspire the 5 research community to continue to develop novel and general catalytic methods for a broad range of substrates under ambient reaction conditions for this highly important synthetic transformation

\section{2. Comments on thermal amidation}

As mentioned above, it is well-known that amides can be formed by the thermal treatment of a carboxylic acid and an amine without any catalyst present, generally at reaction temperatures of ${ }_{15}>140{ }^{\circ} \mathrm{C} .{ }^{11}$ Recently, it was shown that a significant amount of the amide product can be formed even at lower temperatures, usually with azeotropic removal of water. ${ }^{12,13,14}$ The yields of the thermal amidation reaction is highly substrate dependent, as well as dependent on temperature, substrate concentration, solvent and

20 other reaction parameters. As an example, the thermal yield of $N$ (4-methylbenzyl)-3-phenylpropanamide at $110{ }^{\circ} \mathrm{C}$ under neat conditions was reported to be $58 \%$, whereas the same product was formed quantitatively in toluene at $2 \mathrm{M}$ concentration with the same reaction time and temperature (Scheme 1). ${ }^{13}$ For ${ }_{25}$ comparison, the structurally similar $\mathrm{N}$-benzylphenylacetamide was formed in only $13 \%$ yield or less, when phenylacetic acid and benzylamine were allowed to react in THF at $70{ }^{\circ} \mathrm{C}$ at a concentration of $0.4 \mathrm{M}$ and a reaction time of 24 hours. ${ }^{15}$ The literature on thermal amidation is not covered in this review

30 unless the non-catalysed reaction is specifically mentioned by the authors.

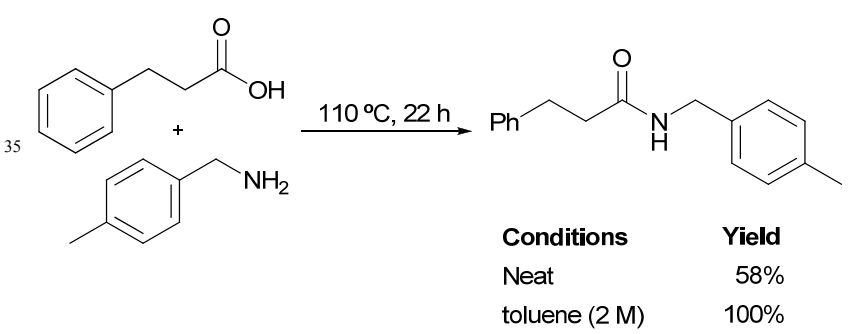

Scheme 1. Condition dependence in thermal amidation (Williams, 2012)

It should be pointed out that the thermal reaction, which 45 indeed gives the targeted amide product, is sometimes not investigated or commented upon throughout the literature. In general, the thermal amide bond formation is not a synthetic problem unless the process involves a kinetic resolution of the starting material. Although the background reaction can be s0 substantial under certain reaction conditions, and sometimes raises the question regarding the importance of the catalyst, an added catalyst is often shown to enhance the reaction rate further. At lower reaction temperatures, the thermal amidation is most often negligible and the product formation can solely be ${ }_{55}$ attributed to the catalytic action. The marked dependence on substrates and reaction conditions for the amide bond formation makes the comparison between different catalytic methods difficult and sometimes not even meaningful at all. Rather, the synthetic utility, practicality and substrate scope of the methods 60 are more important factors to consider in the assessment of the scientific impact.

\section{Biocatalysis}

Enzymes are Nature's own catalysts for a wide variety of reactions, and amide bond formation for the build-up of proteins 65 and other biologically important amides is one of the most central. The highly selective actions of enzymes under ambient conditions, as in most crucial biological processes, have inspired many research groups to utilize biocatalysts for synthetic purposes. Not surprisingly, enzymatic systems have been applied 70 for the catalytic formation of a range of different amides and their derivatives.

\subsection{Catalytic formation of primary amides}

Lipases make up the most common enzyme class used for the 75 synthetic formation of amides from carboxylic acids and amines, with a few exceptions. For example, the amidation of the $\mathrm{C}$ terminus of dipeptides, using a peptide amidase extracted from orange peel was reported by Čeřovský and Kula. ${ }^{16}$ By employing a slight excess of ammonium hydrogen carbonate as ammonia 80 source, the authors reported yields of $22-34 \%$ of the primary amide-dipeptides after 72 hours of reaction time at $40{ }^{\circ} \mathrm{C}$ in acetonitrile containing $5 \%$ water (Scheme 2). The enzyme loading was $80 \mathrm{mg} / \mathrm{mmol}$ substrate at a substrate concentration of $0.05 \mathrm{M}$. The authors claimed that the limiting factor of the 85 reaction, in terms of yield, was the solubility of the dipeptides. It was therefore important to prevent the precipitation of the ammonium dipeptide salt by finding the optimal solvent system for a specific substrate, as well as using an ammonia source which gives rise to a $\mathrm{pH}$ suitable for the enzyme activity. 90

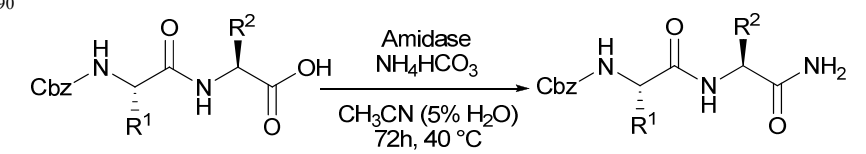

95

$\begin{array}{ll}\text { Peptide } & \text { Yield (\%) } \\ \text { Cbz-Gly-Phe-OH } & 33.5 \\ \text { Cbz-Gly-Leu-OH } & 27.5 \\ \text { Cbz-Leu-Phe-OH } & 23.0 \\ \text { Cbz-Pro-Phe-OH } & 21.5 \\ \text { Cbz-Phe-Ala-OH } & 33.0 \\ \text { Cbz-Ala-Pro-Leu-OH } & 24.0\end{array}$

Scheme 2. Selected primary peptide amides formed using a peptide amidase catalyst (Čeřovský, 1998).

In 2001, the same authors demonstrated that the C-terminals of 105 not only dipeptides but also of different tri- tetra- and pentapeptides could be turned into the primary amide functionality with the amidase catalyst. ${ }^{17}$ The enzyme activity was reported to drop significantly when more than four amino acids were linked together, resulting in a low yield of the Boc110 protected pentapeptide Leu-enkephalin $(<10 \%)$. Peptides derived from D-amino acids were not converted into amides by the enzyme catalyst.

Another useful protocol for the amidation of peptide C- 
terminals was published by Nuijens et al. ${ }^{18}$ The authors used Candida Antarctica lipase B (CAL-B) and cross-linked Subtilisin A protease (Alcalase-CLEA) for the C-terminal amidation of Cbz-protected amino acids, as well as a number of different di-, 5 tri- and tetrapeptides in high yields (Scheme 3). The amide nitrogen was delivered from either ammonium benzoate or directly from the ammonium salts of the amino acids or peptide starting materials. The reactions were run in toluene with a catalyst loading of $100 \mathrm{mg}$ of CAL-B to $50 \mathrm{mg}$ peptide substrate, 10 or in a DMF/t-butanol mixture with a catalyst loading of $50 \mathrm{mg}$ Alcalase-CLEA to $0.1 \mathrm{mmol}$ peptide in the presence of $3 \AA$ molecular sieves. Transamidation and hydrolysis of the starting materials were successfully avoided in the majority of the cases.

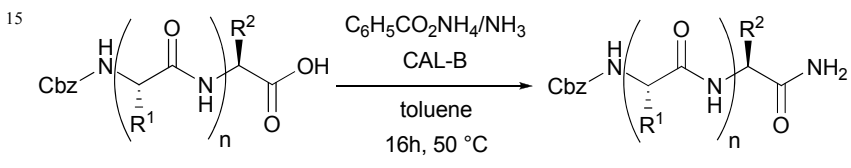

$\mathrm{n}=0,1$ or 2

$\begin{array}{llc}\text { Amino acid / peptide } & \text { Yield (\%) } & \mathbf{N H}_{3} \text { source } \\ \text { Cbz-Pro-OH } & 99 & \text { ammonium benzoate } \\ \text { Cbz-Val-Pro-Pro-OH } & 90 & \\ \text { Cbz-Gly-Leu-Ala-OH } & 65 & \text { ammonia gas } \\ \text { Cbz-Gly-Phe-Ala-OH } & 82 & \vdots \\ \text { Cbz-Gly-Ile-Ala-OH } & 85 & \\ \text { Cbz-Val-Val-Pro-OH } & 56 & \end{array}$

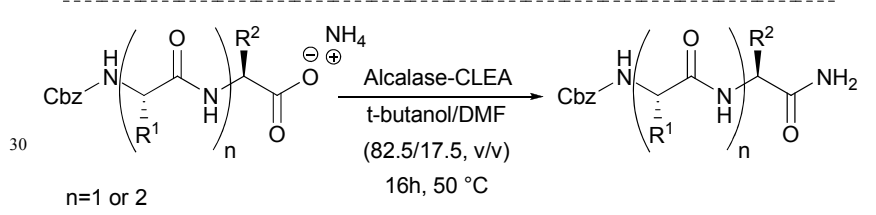

$\begin{array}{ll}\text { Peptide } & \text { Yield (\%) } \\ \text { Cbz-lle-Met-OH } & 89 \\ \text { Cbz-Ala-Phe-OH } & 87 \\ \text { Cbz-Gly-Leu-Ala-OH } & 89 \\ \text { Cbz-Gly-Pro-Ala-OH } & 85 \\ \text { Cbz-Gly-Ile-Ala-OH } & 78 \\ \text { Cbz-Pro-Leu-Gly-OH } & 53\end{array}$

${ }_{40}$ Scheme 3. Selected amidation of peptides catalysed by lipases (Nuijens, 2012).

The formation of primary amides from carboxylic acids using ammonium carbamate as source of ammonia and CAL-B 45 immobilized on a macroporous acrylic resin (Novozym $\left.{ }^{\circledR} 435\right)$ as biocatalyst was reported by Litjens et al. ${ }^{19,20}$ At reaction temperatures of $35-60{ }^{\circ} \mathrm{C}$, the amide products were formed from a range of carboxylic acids in $24-94 \%$ yield (Scheme 4).

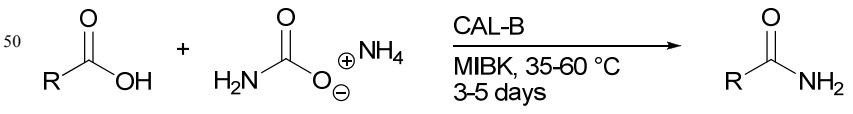

$\begin{array}{llll}\text { Carboxylic acid } & \text { Temp }\left({ }^{\circ} \mathrm{C}\right) & \text { Days } & \text { Yield (\%) } \\ \text { butyric acid } & 35 & 3 & 91 \\ 55 \text { Oleic acid } & 35 & 3 & 94 \\ \text { 2-chloropropionic acid } & 60 & 3 & 24 \\ \text { phenylacetic acid } & 60 & 5 & 87\end{array}$

Scheme 4. Catalytic amidation of carboxylic acids by CAL-B
(Litjens, 1999).

The reaction time was 3-5 days and the synthesis was performed under dilute conditions in methyl isobutylketone (MIBK), using a slight excess of ammonium carbamate and a catalyst loading of $20 \mathrm{mg}$ enzyme per mmol substrate. The authors also ${ }_{65}$ demonstrated that the reaction time could be significantly reduced using diisopropyl ether as solvent, allowing for a higher substrate concentration to be used. The amidation of oleic acid was complete after 6 hours of reaction time, using molecular sieves as water scavenger and the oleamide product was isolated by 70 recrystallization in $79 \%$ yield. However, the catalyst loading for the new protocol was slightly higher compared to the MIBK protocol: $35 \mathrm{mg} / \mathrm{mmol}$ substrate. ${ }^{20}$

Novozym ${ }^{\circledR} 435$ was employed in a continuous plug flow 75 reactor to synthesise oleamide from oleic acid and ammonium carbamate in 2-methyl-2-butanol. ${ }^{21}$ With this experimental setup, the authors claimed that the enzyme cost makes up only $4 \%$ of the total cost by assuming a one year lifetime of the enzyme and a productivity of $4500 \mathrm{~kg}$ amide $/ \mathrm{kg}$ enzyme. It was argued that the 80 volumetric productivity of this setup was a 4 - to a 100 -fold improvement compared to the earlier developed batch methods. Novozym ${ }^{\circledR} 435$ was also used by Levinson et al. to catalyse the formation of the corresponding primary amides of oleic acid, lesquerolic and ricinoleic acid, using ammonium carbamate as ${ }_{85}$ ammonia source. ${ }^{22}$ After 24 hours at $55^{\circ} \mathrm{C}$ and a 1:1 molar ratio of carbamate to acid, the amides were formed in near quantitative yields with a catalyst loading of $100 \mathrm{mg}$ immobilized enzyme to $1 \mathrm{mmol}$ substrate. The same methodology was also efficient for the direct amidation of 10-hydroxystearic acid and 10-ketostearic 90 acid in 2-methyl-2-butanol to obtain the corresponding primary amides in $94 \%$ and $92 \%$ yield respectively. ${ }^{23}$ Furthermore, it was shown that multi-hydroxylated fatty acids were efficiently converted into the corresponding amides employing the same method. ${ }^{24} \mathrm{~A}$ comparison between enzymatic amidation protocols 95 for oleic acid with Novozym ${ }^{\circledR} 435$ as catalyst is given in Scheme 5.

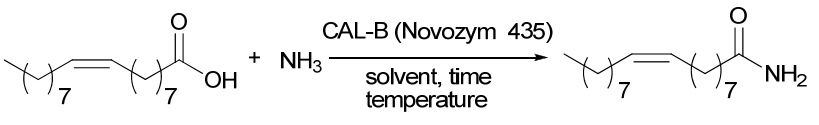

oleic acid

$\begin{array}{llllll}\text { Method } & \text { Solvent } & { }^{\circ} \mathrm{C} & \text { Time } & \text { Catalyst loading } & \text { Yield } \\ \text { Litjens } & \text { MIBK } & 35 & 3 \text { days } & 20 \mathrm{mg} / \mathrm{mmol} & 94 \% \\ \text { Litjens } & \text { diisopropyl ether } & 60 & 6 \mathrm{~h} & 35 \mathrm{mg} / \mathrm{mmol} & 93 \% \\ \text { Slotema } & \text { 2-methyl-2-butanol } & 60 & * & 0.063 \mathrm{mg} / \mathrm{mmol}^{*} & 97 \%^{*} \\ \text { Levinson } & \text { 2-methyl-2-butanol } & 55 & 24 \mathrm{~h} & 100 \mathrm{mg} / \mathrm{mmol} & \text { quant. }\end{array}$
105

* plug flow reactor (fixed bed column, internal diameter $9 \mathrm{~mm}$; length $7 \mathrm{~cm}$ ) with $0.05 \mathrm{ml} / \mathrm{min}$ flow

Scheme 5. Overview of CAL-B -based methods for the formation of oleamide.

The direct amidation with Novozym ${ }^{\circledR} 435$ as catalyst can also be performed in an ionic liquid, as demonstrated by Lau et al. A quantitative yield was obtained for octanamide in 1-butyl-3methylimidazolium tetrafluoroborate $\left(\left[\mathrm{C}_{4} \mathrm{mim}\right]\left[\mathrm{BF}_{4}\right]\right)$ by 115 bubbling ammonia gas through a solution of octanoic acid for 4 days at $40{ }^{\circ} \mathrm{C}$. The catalyst loading was $0.17 \mathrm{mg}$ immobilized 
enzyme to $1 \mathrm{mmol}$ substrate. ${ }^{25}$

In addition to the enzymatic methods above, the microorganisms Bacillus cereus, ${ }^{26,27}$ Streptomyces halstedii, ${ }^{28}$ 5 and Bacillus subtilis ${ }^{29}$ have been used to form primary amides from carboxylic acids.

\subsection{Secondary and tertiary amides}

The first report on the enzymatic formation of secondary amides 10 was published in 1991 by Tuccio et al. ${ }^{30}$ A series of carboxylic acids were converted into the corresponding n-octylamides using Porcine pancreas lipase (PPL), Candida cylindracea lipase (CCL) and two mycelia preparations of Rhizopus arrhizus (RAL) and Penicillum cyclopium (PCL) with lipasic activity. The best 15 result was obtained with RAL and palmitic acid (50\% yield) at 40 ${ }^{\circ} \mathrm{C}$ for 7 days with a $2: 1$ ratio of acid to amine, and a catalyst loading of 2000 lipasic units of enzyme to $1 \mathrm{mmol}$ carboxylic acid. A clear correlation between the length of the carbon chain in the carboxylic acid substrate and product yield was observed; 20 only $25 \%$ yield of the product was obtained with acetic acid (Scheme 6). In addition to the desired secondary amides, imide and amidine by-products were formed in low yields during the reaction.

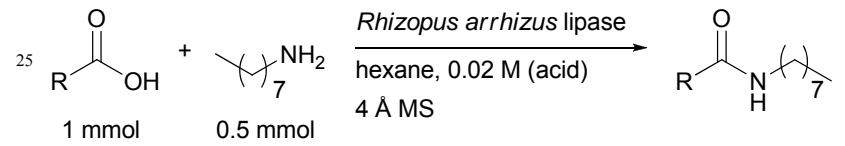

$30 \quad \begin{array}{ll}\mathbf{R} & \text { Yield (\%) } \\ \mathrm{CH}_{3} & 25 \\ \mathrm{C}_{3} \mathrm{H}_{7} & 30 \\ \mathrm{C}_{7} \mathrm{H}_{15} & 35 \\ \mathrm{C}_{15} \mathrm{H}_{23} & 40 \\ \mathrm{C}_{15} \mathrm{H}_{31} & 50\end{array}$

${ }_{35}$ Scheme 6. Rhizopus arrhizus lipase-catalysed amidation of carboxylic acids of different chain lengths (Tuccio, 1991).

In 2002, the first protocol employing a protease as biocatalyst for the direct amidation of carboxylic acids was published by ${ }_{40}$ Ulijn et al. ${ }^{31}$ It was also the first paper to describe the catalytic formation of peptides from two amino acids under synthetically useful reaction conditions. The amine component of the reaction,

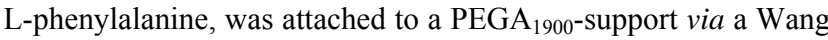
linker and then reacted with a variety of protected amino acids in ${ }_{45}$ aqueous media with thermolysin as catalyst. The peptides were obtained in good to excellent yields after hydrolysis, using a catalyst loading of $25 \mathrm{mg}$ per mmol substrate. Amino acids with non-polar side chains gave the highest conversions, and interestingly, no product was observed with the non-natural

50 amino acid Fmoc-norleucine (Scheme 7). An important factor for the success of this method is that the ionization of the supported amine substrate can be supressed by the proximity to the positively charged resin.

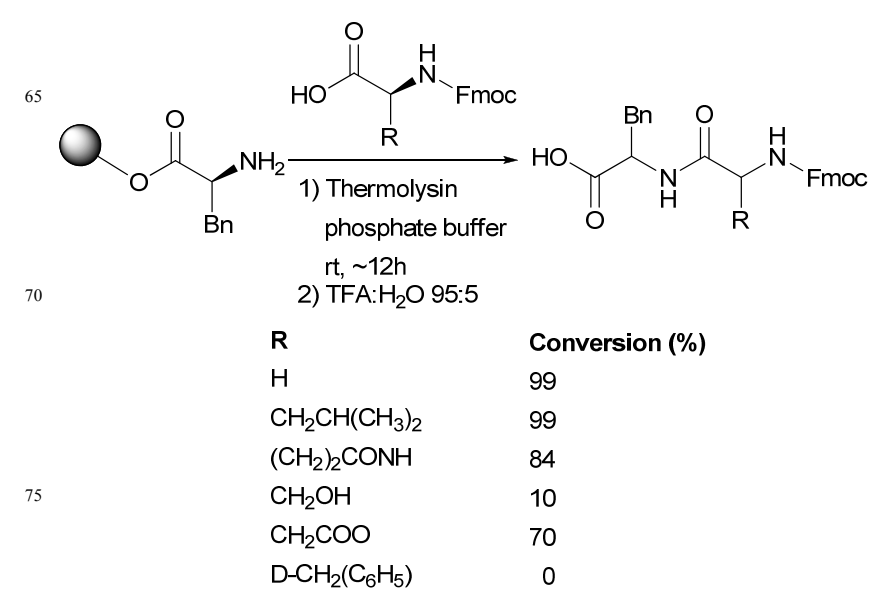

Scheme 7. Selected dipeptides formed in thermolysin-catalysed 80 amidation (Ulijn, 2002).

The enzyme-catalysed formation of surfactants based on biologically derived starting materials has been rather wellinvestigated. The first example of this was published in 1997, 85 when Maugard et al. reported on the bio-catalysed synthesis of surfactants from oleic acid and the sugar $\mathrm{N}$-methyl-glucamine. ${ }^{32}$ Yields of up to $97 \%$ were obtained at $90{ }^{\circ} \mathrm{C}$ with immobilized Candida Antarctica lipase B (Novozym $\left.{ }^{\circledR} 435\right)$ after 50 hours of reaction time. The molar ratio of acid to amine was $1: 1$ in 2 90 methyl-2-butanol with a catalyst loading of $57 \mathrm{mg}$ immobilized enzyme to $1 \mathrm{mmol}$ substrate. The authors reported that the amide coupling also worked well using decanoic acid or $N$-methylgalactamine as substrates (Scheme 8). A high selectivity between amidation and esterification of the primary alcohol of the ${ }_{95}$ glucamine could be achieved by controlling the acid/amine ratio, and hence the $\mathrm{pH}$, of the reaction medium. Kinetic studies showed that an excess of the carboxylic acid favoured the ester formation whereas an excess of the amine component favoured the amide product. ${ }^{33}$ The same selectivity trend was observed 100 when the reaction was performed in hexane with immobilized Rhizomucor miehei lipase (Lipozyme ${ }^{\circledR}$ ) in place of CAL-B. However, lower conversions into the amide product were observed when Lipozyme ${ }^{\circledR}$ was employed as catalyst. ${ }^{34}$ The mechanism and origin of selectivity of the immobilized CAL-B 105 was investigated, as well as the kinetics of $O$ - vs $N$-acylation of myristic acid with 2-butanol and sec-butylamine. ${ }^{35,36}$
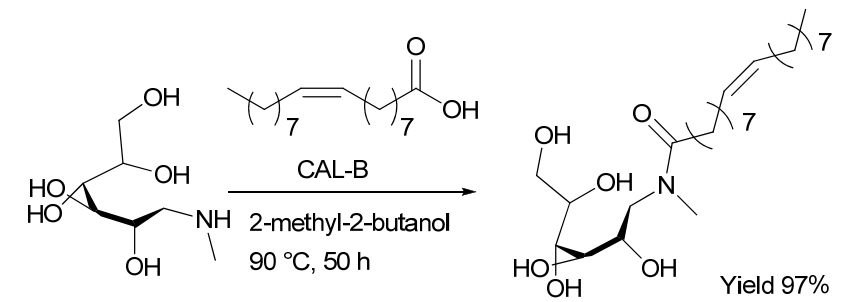

${ }_{115}$ Scheme 8. Amide formation from oleic acid and $N$-methylglucamine (Maugard, 1997). 
The catalytic amidation of ethanolamine with fatty acids was studied by Fernandez-Perez and Otero. It was found that high yields (90-94\%) of the amide surfactants could be obtained using ${ }_{5} \operatorname{Novozym}^{\circledR} 435$ as amidation catalyst. ${ }^{37}$ An equimolar ratio of ethanolamine and carboxylic acid was used in dioxane, acetonitrile or n-hexane at $40{ }^{\circ} \mathrm{C}$ (Scheme 9). The catalyst loading was generally $125 \mathrm{mg} / \mathrm{mmol}$ substrate, and the reaction was found to be highly selective for $N$ - over $O$-acylation. However, 4${ }_{10} 6 \%$ of the diacylated product was formed in dioxane and acetonitrile as solvent. Not too surprisingly, the diacylated product was favoured by an excess of the fatty acid; a 2-4 molar excess of the carboxylic acid gave rise to $70-90 \%$ yield of the $\mathrm{N}, \mathrm{O}$-diacylated product.

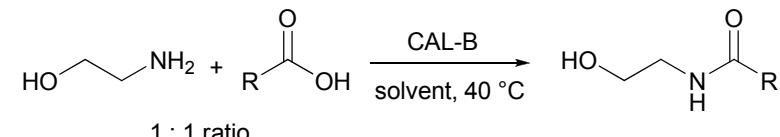

$$
\begin{aligned}
& \begin{array}{lll}
\text { Acid } & \text { R } & \text { Yield (\%) }
\end{array}
\end{aligned}
$$

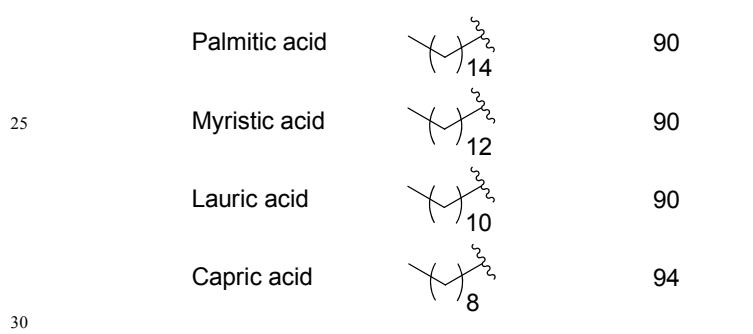$$
20
$$

Scheme 9. Amidation of ethanolamine with long-chain carboxylic acids (Fernandez-Perez, 2001).

Additional studies by Fernandez-Perez and Otero on secondary 35 amines concluded that an excess of diethanolamine resulted in full chemoselectivity in favour of the tertiary amide product. ${ }^{38}$ It was also found that the monoacylated ester was a rapidly formed intermediate in dioxane, which subsequently was transformed into the thermodynamically more stable amide. However, no such 40 ester intermediate was observed when the reaction was performed in n-hexane.

Tufvesson et al. published a large scale synthesis of the ethanolamide of lauric acid ( $100 \mathrm{~g}$ lauric acid, $0.5 \mathrm{~mol})$, using ${ }_{45}$ Novozym ${ }^{\circledR} 435$ as catalyst $(5 \mathrm{~g})$ and an equimolar mixture of acid and amine. ${ }^{39}$ By running the reaction at $90{ }^{\circ} \mathrm{C}$ and adding the ethanolamine in portions to keep it protonated at all times, water could be distilled off under vacuum to afford the surfactant amide in $95 \%$ yield. Surfactant ethanolamides were also synthesised by ${ }_{50}$ Plastina et al. ${ }^{40}$ Novozym ${ }^{\circledR} 435$ was used as catalyst to afford six different ethanolamides from fatty acids in yields ranging from $80-88 \%$. The reaction was performed in hexane at $40{ }^{\circ} \mathrm{C}$, with a catalyst loading of $250 \mathrm{mg} / \mathrm{mmol}$ substrate and a 1:1 molar ratio of amine to acid. The immobilized enzyme was also used by ${ }_{55}$ Wang et al. for the amidation of oleic acid with ethanolamine on a $50 \mathrm{mmol}$ scale, yielding $74 \%$ of the amide after recrystallization. ${ }^{41}$ The catalyst loading was $30 \%$ and the reactants were used in a 1:1 molar ratio.
60 The effect of microwave irradiation on the enzyme-catalysed (Novozym ${ }^{\circledR} 435$ ) formation of ethanolamides from fatty acids was investigated by Kidwai and co-workers. ${ }^{42}$ It was found that the reaction proceeded considerably faster with microwave induced synthesis as compared to conventional heating (reaction ${ }_{65}$ times of minutes instead of hours). Furthermore, when the reactants were impregnated on the supported enzyme, the amidation reaction was more efficient compared to performing the reaction in solution (Scheme 10). The optimized catalyst loading was reported to be $8 \mathrm{mg} / \mathrm{mmol}$ substrate.

70

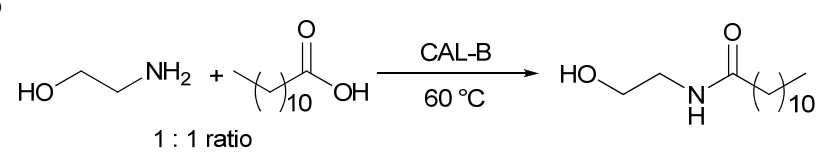

Type of heating

Reactant addition

MWI

$\mathrm{MWI}$

reactants in 1,4-dioxane

Time (min) Yield (\%)

$180 \quad 87$

$50 \quad 92$

reactants impregnated $\quad 5 \quad 97$

onto the supported enzyme

${ }_{80}$ Scheme 10. Amidation of ethanolamine with conventional vs. MW heating (Kidwai, 2009).

Kidwai et al. also found that primary amides as well as $N$-methyland $N$-ethylamides could be formed with Novozym ${ }^{\circledR} 435$ using ${ }_{85}$ PEG200, PEG400 and PEG600 as solvents. ${ }^{43}$ With equimolar amounts of the amine and carboxylic acid, the amides were formed in $60-88 \%$ yield from lauric, capric, myristic and palmitic acid. Molecular sieves were used as a water scavenger at room temperature and the catalyst loading was reported to be 25 $90 \mathrm{mg} / \mathrm{mmol}$ substrate. The results from the PEG reactions were shown to be comparable to, and sometimes better than, results from reactions in ionic liquids or $t$-butanol. The authors showed that the immobilized enzyme could be reused up to 8 times with only $5 \%$ difference in yield between the first and the eighth run.

Novozym ${ }^{\circledR} 435$ has also been used for the amidation of $(E)$ 7,10-dihydroxydec-8-enoic acid with $N$-methylethanolamine, resulting in a yield of $95 \%$ after 72 hours at $50{ }^{\circ} \mathrm{C}$ in isoamyl alcohol. ${ }^{44}$ In addition, the same catalyst was employed for the 100 biosynthesis of 18 different $\mathrm{N}$-alkylamides under solvent-free conditions and reduced pressure. The products were obtained in $77-82 \%$ yield, and four of them were found to have biological activity against root-knot nematode (Meloidogyne incognita). ${ }^{45}$

\section{3.3 Hydroxamic acids and acyl hydrazines}

One of the first reports on the enzymatic synthesis of hydroxamic acids from a sodium acyl salt and hydroxylamine was reported by Lipmann and Tuttle in $1950 .{ }^{46}$ With the use of a hog liver esterase and the pancreas lipase Pancreatine Parke-Davis, the 110 authors reported on the formation of hydroxamic acids in yields typically around $10 \%$ after 60 minutes incubation time at $37^{\circ} \mathrm{C}$ at neutral $\mathrm{pH}$. It was found that the two enzymes functioned optimally with carbon chains of different lengths; the hog liver esterase worked best with sodium octanoate, whereas the longer 115 chain of sodium dodecanoate suited the pancrease lipase better. Hydroxylamine was used in large excess in all the reported 
examples.

A synthetically useful method for the synthesis of aliphatic hydroxamic acids was reported by Servat et al. ${ }^{47}$ Yields around $575 \%$ were obtained for a range of aliphatic acids with a chain length of 8-22 carbons (Figure 1), using Lipozyme ${ }^{\circledR}$ as catalyst. The reaction was performed at $37^{\circ} \mathrm{C}$ with a reaction time of 24 hours, with a five-fold excess of the hydroxylamine to acid substrate in a phosphate buffer $(\mathrm{pH} 7)$ and a catalyst loading of $10250 \mathrm{mg}$ immobilized enzyme per $1 \mathrm{mmol}$ substrate.<smiles>CC(C)(C)C(=O)O</smiles>

15

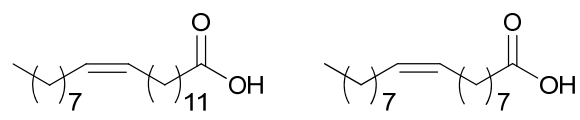

20<smiles>CCC=CCC=CC(C)C(=O)O</smiles>

Figure 1. Substrates used for the formation of hydroxamic acids by Servat et al. (1990).

25 Sheldon and co-workers reported on the gram-scale formation of $\mathrm{N}$-hydroxyoctanamide from octanoic acid and hydroxylamine (93\% yield), using Novozym ${ }^{\circledR} 435$ in organic solvents at $40{ }^{\circ} \mathrm{C}$. The catalyst loading was $1.44 \mathrm{mg}$ immobilized enzyme to 1 mmol substrate using a slight excess of the aqueous 30 hydroxylamine (1.24 equiv). ${ }^{48}$ It was found that the reaction performed equally well with $T$. lanuginosus lipase immobilized on Accurel EP 100 as catalyst. Furthermore, $O$ benzylhydroxylamine, as well as different hydrazines could be used as coupling partners to form the corresponding carboxylic 35 derivatives in excellent yields in $t$-butanol at $40{ }^{\circ} \mathrm{C}$ (Scheme 11). When hydrazine was used as substrate in the reaction with an excess of octanoic acid, $N, N^{\prime}$-dioctoylhydrazine was obtained in good yields. $^{49}$

40<smiles>[X]NCC(C)(C)C(=O)O</smiles>

$45 \quad \mathrm{X}=\mathrm{OPh}, 66 \% \quad \mathrm{X}=\mathrm{NHPh}, 95 \%$

$\mathrm{X}=\mathrm{OBn}, 98 \% \quad \mathrm{X}=\mathrm{NHBz}, 96 \%$

$\mathrm{X}=\mathrm{NH}_{2}, 91 \%$

Scheme 11. Enzymatic synthesis of hydroxamic acids and acyl 50 hydrazines from octanoic acid (Sheldon and co-workers, 2000).

\subsection{Kinetic resolution of amines or carboxylic acids}

In a kinetic resolution (KR), a chiral catalyst discriminates between two enantiomers of a substrate by reacting faster with 55 one of the isomers. If the catalyst is completely selective, the maximum yield of the process is $50 \%$ with a product of $100 \%$ enantiomeric excess (ee). In a dynamic kinetic resolution (DKR), a selective chiral catalyst is combined with a racemising agent/catalyst, which produces both enantiomers of the substrate 60 throughout the reaction. The combination of the two enables a theoretical maximum yield of $100 \%$ of the fully enantiomerically enriched product.

The first example of enzymatic kinetic resolution of a chiral ${ }_{65}$ carboxylic acid in the amidation with an amine was published by Litjens et al. in $1999 .^{20}$ The authors demonstrated that 4methyloctanoic acid could be resolved by turning it into the primary amide using Novozym ${ }^{\circledR} 435$ (20 mg immobilized enzyme per $1 \mathrm{mmol}$ substrate, Scheme 12). An excess of 70 ammonium carbamate was used as source of ammonia, resulting in $52 \%$ conversion and $95 \%$ ee in favour of the $(R)$-enantiomer. The ee was determined by measurements on the remaining unreacted carboxylic acid.

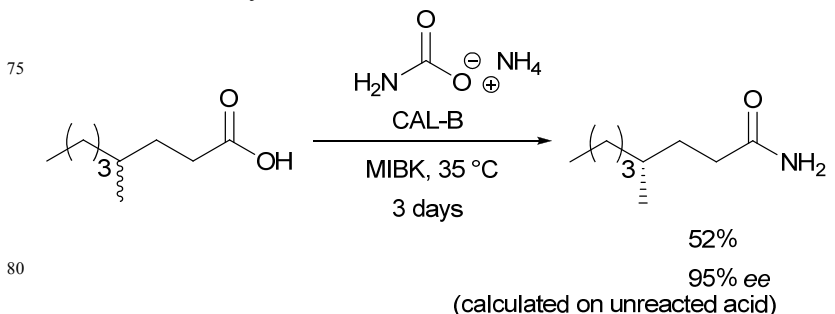

Scheme 12. Kinetic resolution of 4-methyloctanoic acid with CAL-B (Litjens, 1999).

85 Sheldon and co-workers showed that racemic ibuprofen could be kinetically resolved as its hydroxamic acid with Candida rugosa lipase (ChiroCLEC-CR) in $41 \%$ yield with $>92 \%$ ee as the (S)-isomer (catalyst loading of $50 \mathrm{mg}$ per mmol substrate). The racemic acid could also be resolved as its octanoylhydrazine 90 derivative with the best result arising from the use of Pseudomonas lipoprotein lipase in $50 \%$ yield with $82 \%$ ee as the $(R)$-enantiomer (Figure 2). ${ }^{49}$

The enzymatic dipeptide synthesis from protected amino acids 95 on solid support, reported by Ulijn et al., was also shown to be active in kinetic resolution. ${ }^{31}$ The authors showed that the protease catalyst was selective for only one of the stereoisomer of phenylalanine, producing only the L,L-diastereomer when Lphenylalanine on solid support was reacted with Fmoc-protected 100 D,L-phenylalanine (Figure 2).

The enzymatic kinetic resolution of chiral amines by amidation with carboxylic acids was first published by Tuccio et al. in $1991{ }^{30}$ It was found that the kinetic resolution of racemic 2105 aminooctane with palmitic acid could be performed, using Rhizopus arrhizus lipase as catalyst. The (R)-enantiomer of the amine preferentially reacted with the acid, resulting in a yield of $30 \%$ and an enantiomeric excess of $70 \%$ of the amide product (Figure 2). Further studies by Irimescu and Kato showed that 110 Novozym ${ }^{\circledR} 435$ could be employed for the kinetic resolution of 1-phenylethylamine and 2-phenyl-1-propylamine in the amidation reaction with octanoic, dodecanoic and 4-pentenoic acid. The reaction was performed in ionic liquids under reduced pressure $(5 \mathrm{~mm} \mathrm{Hg})$ and a catalyst loading of $23 \mathrm{mg} / 1 \mathrm{mmol}$ ${ }_{115}$ substrate. ${ }^{50}$ When 1-phenylethylamine was used as substrate, the amide products were obtained with excellent enantioselectivities 
(97->99\% ee) in yields ranging from 8 to $49 \%$. The analogous reaction with 2-phenyl-1-propylamine displayed considerably lower selectivity; $59.8 \%$ ee was obtained under solvent free conditions (Figure 2). Further studies revealed that the amide 5 from 1-phenylethylamine and 4-pentenoic acid was obtained in low to moderate yields (5-21\%) and excellent enantioselectivities ( $>99 \%$ ee in favor of the $(R)$-isomer). ${ }^{51}$ The highest yield was obtained in 1-butyl-2,3-methylimidazolium trifluormethane sulphonate ([bdmim]tfms), when the reaction was performed 10 under reduced pressure at slightly elevated temperature. Performing the reaction with $3 \mathrm{mmol}$ carboxylic acid resulted in $41 \%$ conversion and $>99 \%$ ee of the resulting amide. Prasad et al. reported on the kinetic resolution of racemic 2-ethylhexyalmine in the amidation reaction with six different carboxylic acids, 15 using CAL-B immobilized on accurel as catalyst at $90{ }^{\circ} \mathrm{C}$ under solvent free conditions and vacuum. ${ }^{52}$ The amides were obtained in $40-45 \%$ yield with $>99 \%$ ee employing a catalyst loading of $120 \mathrm{mg} / \mathrm{mmol}$ carboxylic acid and 2 equivalents of the amine (Figure 2). Bertrand and co-workers reported on the use of 20 Novozym ${ }^{\circledR} 435$ for the kinetic resolution of racemic amines at 80 ${ }^{\circ} \mathrm{C}$ in heptanes with a 1:1 molar ratio of carboxylic acid to amine (catalyst loading of $200 \mathrm{mg} / \mathrm{mmol}$ substrate). ${ }^{53}$ The authors demonstrated that the enzyme could be used for the kinetic resolution of 2-amino-4-phenylbutane with four different 25 carboxylic acids, resulting in high yields and excellent enantioselectivities for the $(R)$-isomer of the amides. Lauric acid was also used as acylating agent for a range of amines, resulting in good yields with good to excellent $e e$ 's of most amides. However, the resolution of 2-phenylethylamine resulted in a 30 moderate $65 \%$ ee of the corresponding amide (Figure 2). Furthermore, the authors showed that the immobilized enzyme could be recycled five times, with only negligible changes in yield and enantioselectivity of the amide product.

35 Bertrand and co-workers reported on the dynamic kinetic resolution (DKR) of amines using the Novozym ${ }^{\circledR} 435$ catalyst, in combination with AIBN and a thiol at $80{ }^{\circ} \mathrm{C}$ in heptane. This is the first and only example of DKR in direct amidation. The amidation of 4-phenyl-2-aminobutane, using lauric acid as acyl 40 donor, resulted in $71 \%$ isolated yield and $>99 \%$ ee of the amide, in favor of the $(R)$-enantiomer. The mechanism was suggested to go via a free radical racemization of the amine (Scheme 13). ${ }^{54}$<smiles>C[C@H](N)CC[PH2+][CH]C(=O)C(=O)O</smiles>

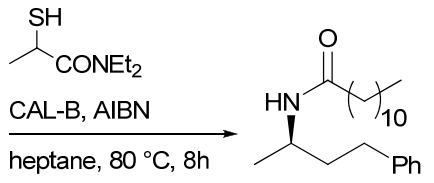

$71 \%,>99 \%$ ee of amidase and protease catalysts, lipases stand out as the most well-established catalyst type for the transformation. Among 60 these, Candida antarctica lipase B is most often the biocatalyst of choice, working well in several solvents, at different temperatures and with a variety of substrates.

Biocatalysts are usually very selective and the enzyme${ }_{65}$ catalysed protocols generally show good selectivity for $\mathrm{N}$ - versus $\mathrm{O}$-acylation. In addition, there are several examples of highly selective kinetic resolution and even an example of dynamic kinetic resolution. A drawback with enzyme-based catalysts is the pre-determined preference for either the $(R)$ - or $(S)$-isomer, which 70 can be of concern if the opposite enantiomer is the synthetic target. Moreover, the synthetic scope is often limited to substrates with similar structures and the reaction times are sometimes in terms of days. These issues could be addressed e.g. by directed evolution, ${ }^{55}$ and bioengineering.

75

Many biocatalytic protocols employ enzymes immobilized on a solid support, e.g. Novozym ${ }^{\circledR} 435$. The use of a solid-supported enzyme makes it possible to recycle the catalyst and also enables the use of flow reactors. This has been demonstrated in the 80 literature and those processes are valuable contributions towards greener and more cost-effective syntheses of amides.

Scheme 13. Free radical mediated dynamic kinetic resolution of ${ }_{50}$ an amine using CAL-B as catalyst (Bertrand, 2007).

\subsection{Summary and conclusions on biocatalysis}

The enzyme-catalysed amide bond formation has been explored 55 by several groups for the formation of primary, secondary and tertiary amides, as well as carboxylic derivatives of hydroxylamines and hydrazines. Even though there are examples 115

This journal is (C) The Royal Society of Chemistry [year] Journal Name, [year], [vol], 00-00 | 7 
Litjens et al. 1999

(Candida antarctica lipase B)

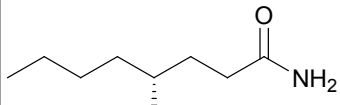

$52 \%$

95\% ee (calculated on unreacted acid)

Sheldon and co-workers 2001

(Candida rugosa lipase and

Pseudomonas lipoprotein lipase)

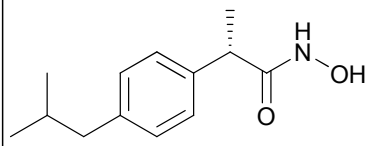

$41 \%$

$>92 \%$ ee

$50 \%$

$82 \%$ ee

Ulijn et al. 2002

(Thermolysin)

$\mathrm{Fmoc}_{\mathrm{NH}}^{\mathrm{Fmoc} \mathrm{O}}$

$49.5 \%$

$>99 \%$ de

Tuccio et al. 1991

(Rhizopus arrhizus lipase)

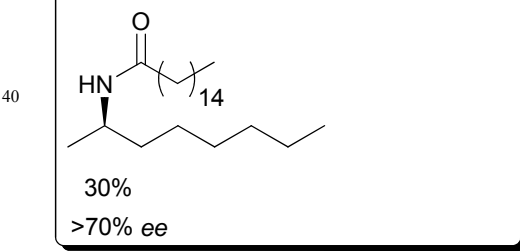

45

Irimescu et al. 2004

(Candida antarctica lipase B)
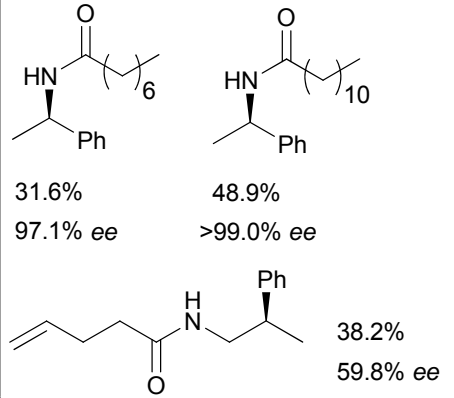

Prasad et al. 2005

(Candida antarctica lipase B)

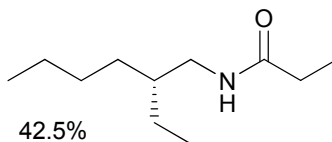

$>99 \%$ ee

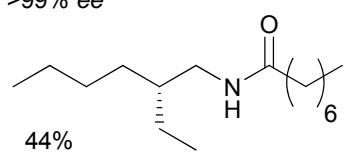

$>99 \%$ ee

ee calculated on unreacted acid<smiles>CCCC[C@H](CC)CNC(=O)C(C)(C)C</smiles>

$>99 \%$ ee

$>99 \%$ ee<smiles>CCCC[C@H](CC)CNC(=O)C(C)C</smiles>

$>99 \%$ ee

Bertrand and co-workers 2007

(Candida antarctica lipase B)

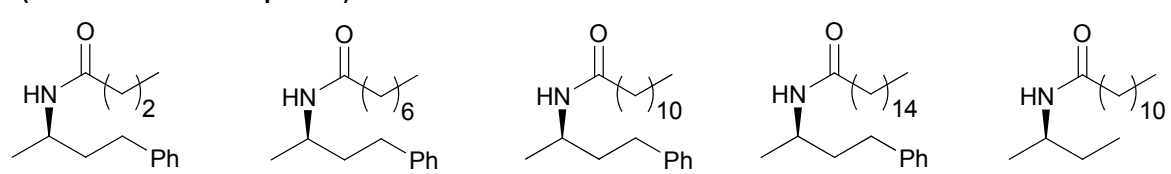

$44 \%$ (NMR)

$97.1 \%$ ee

$48 \%$

$98.6 \%$ ee

$45 \%$ (NMR)

$49 \%$

$55 \%$<smiles>CC(NC(=O)CC(C)(C)C)C(C)(C)C</smiles><smiles>CC(NC(=O)C(C)(C)CC(C)(C)C)C(C)(C)C</smiles>

$>99.5 \%$ ee

$>99.5 \%$ ee

$65.0 \%$ ee<smiles>CC(C)CCC[C@H](C)NC(=O)C(C)(C)C</smiles><smiles>CC(C)=CCC[C@H](C)NC(=O)CC(C)(C)C</smiles>

$45 \%$

$96.9 \%$ ee

$45 \%$

$>99.5 \%$ ee

$38 \%$

$42 \%$<smiles>CCN(CC)CCC[C@H](C)NC(=O)C(C)(C)C</smiles><smiles>C[C@H](NC(=O)CC(C)(C)C)C1CCCCC1</smiles>

$44 \%$

$99.8 \%$ ee

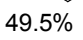

$99.0 \%$ ee

$99.5 \%$ ee<smiles>Cc1cccc(C)c1OCC(C)NC(=O)C(C)(C)C</smiles>

$39 \%$

$>98.0 \%$ ee<smiles>C=CCCC(=O)N[C@@H](C)c1ccccc1</smiles>

$8 \%$

$>99.0 \%$ ee<smiles>C[C@H](CPc1ccccc1)NC(=O)C(C)(C)CC(C)(C)C</smiles><smiles>[Y]C(C)(C)C(=O)N[C@@H](C)c1cccc2ccccc12</smiles>

$48 \%$

$94.0 \%$ ee<smiles>CC(NC(=O)C(C)(C)CC(C)(C)O)c1ccccc1</smiles>

$46 \%$

$98.0 \%$ ee
$46 \%$

$99.0 \%$ ee<smiles>[Y2]C(C)(C)CC(=O)N[C@H]1CCCc2ccccc21</smiles>

$42 \%$

$96.7 \%$ ee<smiles>[Y]C(C)(C)C(=O)N[C@H]1CCc2ccccc21</smiles>

$47 \%$

$>99.5 \%$ ee

Figure 2. Enantiomerically enriched amides from enzyme-catalysed kinetic resolution of racemic substrates. 


\section{Boron-based catalysts for amidation reactions}

The stoichiometric use of boron-based compounds for the direct amidation of non-activated carboxylic acids with amines has been known since the 1960 's. ${ }^{56}$ However, in the last few decades, the 5 use of boron-based compounds as catalysts has gained a considerable interest. The Lewis acidity of the boron-based catalysts can efficiently be fine-tuned by substituent effects for the activation of carboxylic acids. In general, boronic acids and their derivatives show a high functional group tolerance and are 10 more stable in the presence of water compared to other Lewis acids, making them promising catalysts for the direct amidation reaction. However, these types of catalysts commonly require removal of formed water as well as elevated temperatures in order to enable high yields of amide product. Both heterogeneous

15 and homogeneous systems have been developed for boron-based catalysts.

\subsection{Homogeneous boron-catalysed protocols}

The range of soluble boron compounds used as catalysts for the 20 direct amidation of carboxylic acids and amines encompasses boric acid, boric esters, and boronic acids. Of the latter, especially electron-deficient compounds have found their use as catalysts, however, high catalytic activity has also been found in arylboronic acids containing electron-donating groups. ${ }_{25}$ Furthermore, bifunctional arylboronic acids substituted with a tertiary amine have successfully been employed as catalysts.

\subsubsection{Formation of primary amides}

To date, only one boron-based catalytic system is known for the 30 formation of a primary amide from one single substrate. Shteinberg demonstrated that boric acid in combination with PEG-400 are effective in the catalytic amidation of 4nitrobenzoic acid using gaseous ammonia. ${ }^{57}$ Interestingly, neither boric acid nor PEG-400 was catalytically active alone in the 35 absence of the other component. Under optimized conditions, using $2 \mathrm{~mol} \%$ boric acid and $1 \mathrm{~mol} \%$ PEG-400 in refluxing 1,2,4trichlorobenzene (bp $170-175^{\circ} \mathrm{C}$ ), 4-nitrobenzamide was formed in $92 \%$ yield after 10 hours (Scheme 14). ${ }^{58}$<smiles>O=C(O)c1ccc([N+](=O)[O-])cc1</smiles><smiles>NC(=O)c1ccc([N+](=O)[O-])cc1</smiles>

${ }_{45}$ Scheme 14. Formation of 4-nitrobenzamide by boric acid/PEGcatalysis (Shteinberg, 2003 and 2005).

Additionally, PEG of different chain lengths were shown to work well as co-catalysts with boric acid for the formation of primary 50 amides. ${ }^{59,60}$

\subsubsection{Secondary and tertiary amides}

The first boron-based catalytic protocol for the formation of secondary and tertiary amides was reported by Yamamoto and ${ }_{55}$ co-workers in $1996 .{ }^{61}$ It was found that electron-poor arylboronic acids were efficient catalysts for the amide formation in refluxing toluene, xylene or mesitylene with molecular sieves present in a soxhlet thimble. With $1-10 \mathrm{~mol} \%$ of the added $3,4,5-$ trifluorobenzeneboronic acid catalyst, good to excellent yields of 60 secondary and tertiary amides were obtained from aliphatic and aromatic acids with aliphatic and aromatic amines (Scheme 15).

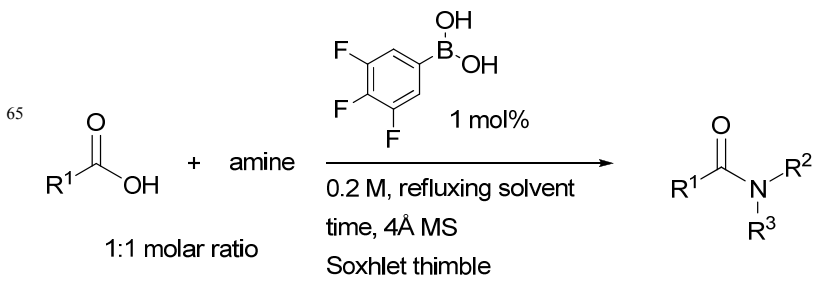

70

$\begin{array}{llll}\text { Solvent } & \begin{array}{l}\text { Time (h) } \\ 18\end{array} & \begin{array}{l}\text { Yield (\%) } \\ 96\end{array} \\ \text { toluene } & \begin{array}{l}\text { Amine } \\ \mathrm{BnNH}_{2}\end{array} & 189 & 96 \\ \text { xylene } & 29 & 99\end{array}$

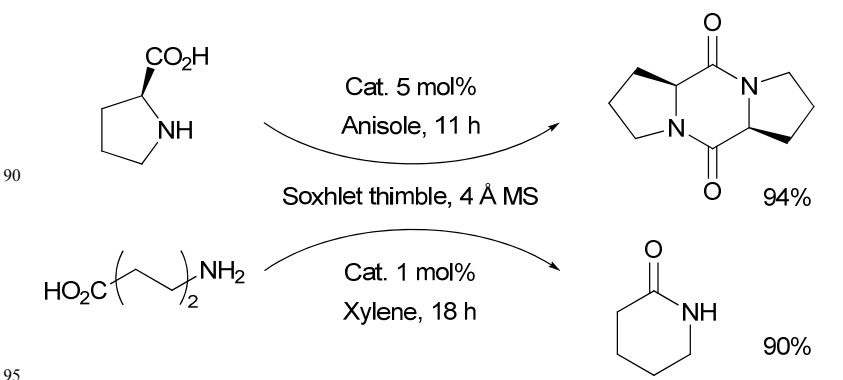

Scheme 15. Selected substrates from Yamamoto and coworkers (1996).

Lactams from 6-aminocapric acid and 5-aminovaleric acid, as 100 well as dimers of unprotected proline were also obtained in good yields using this methodology. The benzyl amides of enantiomerically pure $\alpha$-hydroxy-iso-butyric acid and $\alpha$-hydroxyiso-propanoic acid were formed without any racemisation, whereas the enantiopurity of the mandelic acid product was 105 somewhat reduced during the amide bond formation. The same catalyst was also employed for the poly-condensation reaction of amides to form aliphatic and aromatic polyamides, ${ }^{62}$ and for the synthesis of acyl azides. ${ }^{63}$ For sterically more demanding substrates such as cyclohexylcarboxylic acid and 110 adamantylcarboxylic acid, boron catalysts with a tetrachlorocatechol moiety (Figure 3 ) were found to be more efficient. $^{64}$ 
<smiles>Clc1c(Cl)c(Cl)c2c(c1Cl)OBO2</smiles><smiles>OB1Oc2c(Cl)c(Cl)c(Cl)c(Cl)c2O1</smiles>

Figure 3. Tetrachlorocatechol-based boron catalysts developed by Yamamoto and co-workers (2006).

10 Ishihara and co-workers recently demonstrated that alkylboronic acids are effective catalysts for the amidation of $\alpha$ hydroxy carboxylic acids in refluxing toluene with azeotropic removal of water (Scheme 16). ${ }^{65}$ Interestingly, the addition of water $(2-20 \mathrm{~mol} \%)$ and benzoic acid was found to increase the 15 product yield, possibly by promoting ligand exchange between the product and starting material. (R)-Mandelic acid was found to give partly racemised amides when the reaction was performed in refluxing toluene, whereas (S)-3-phenyllactic acid did not show any decrease in amide enantiopurity under the same reaction 20 conditions. In refluxing 1,2-dichloroethane (bp $83{ }^{\circ} \mathrm{C}$ ), the racemisation of mandelic amides was found to be less pronounced.

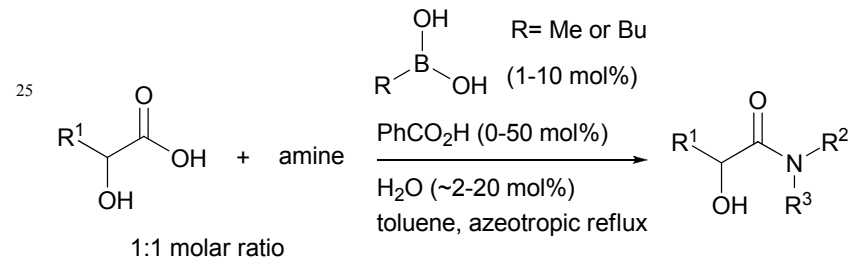

30

$$
{ }_{35} \overbrace{\mathrm{OH}}^{\mathrm{O}}
$$<smiles>CC(C)C(O)C(=O)NC(c1ccccc1)c1ccccc1</smiles>

$96 \%$<smiles>O=C(NCCc1ccccc1)[C@H](O)c1ccccc1</smiles><smiles>COc1ccc(C(O)C(=O)NCCc2ccc(OC)c(OC)c2)cc1</smiles>

$98 \%, 79 \%$ ee

$97 \%$

Scheme 16. Amidation of $\alpha$-hydroxycarboxylic acids with 45 alkylboronic acid catalysis (Ishihara, 2013).

The benzyl amide of salicylic acid was formed in a quantitative yield with the alkylboronic acid catalyst in refluxing o-xylene. A high selectivity for the amide bond formation over esterification ${ }_{50}$ was observed with methylboronic acid as catalyst in the reaction of mandelic acid and 6-aminohexanol as substrates. The thermal background reaction of mandelic acid with 3,5dimethylpiperidine was found to be non-existent in refluxing toluene after 14 hours.

The use of boric acid as catalyst for the formation of secondary and tertiary amides was recently studied by Tang. Both aliphatic and aromatic carboxylic acids and amines were coupled in the presence of $1 \mathrm{~mol} \%$ boric acid in refluxing toluene or xylene to 60 furnish the amide products in $60-99 \%$ isolated yields (Scheme 17). ${ }^{66,67}$ A Dean-Stark trap was used for the removal of water and the protocol was efficient also for substrates containing free hydroxylgroups with full selectivity for $\mathrm{N}$-acylation. The methodology was later used for the synthesis of several active ${ }_{65}$ pharmaceutical compounds, ${ }^{68}$ as well as for the synthesis of substituted cinnamides. ${ }^{69}$

$$
\text { 30 mmol scale }
$$

Scheme 17. Large scale amidation with boric acid catalysis 75 (Tang, 2005).

In 2006, Whiting and co-workers presented an investigation on the kinetics of the direct thermal amidation of carboxylic acids and amines. ${ }^{70}$ The results of the purely thermal reaction were 80 compared to reactions run with boric and boronic acid catalysts. It was concluded that the addition of boronic acid enhanced the reaction rate and in particular, bifunctional boronic acid catalysts were highlighted as a promising type of catalysts for the reaction. The electronic effects of substituted analogues of the bifunctional 85 catalyst were investigated, showing an enhanced catalytic activity for arylboronic acids having a $\mathrm{CF}_{3}$-group in the para position. The opposite effect was observed when the electron donating methoxy group was situated in ortho position (Figure 4). ${ }^{71}$

90<smiles>O=NP=NCc1ccccc1O</smiles>

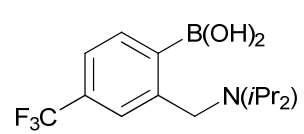<smiles>COc1cccc(CNCCCO)c1OC</smiles>

Figure 4. Developed Bi-functional catalysts (Whiting, 2006)

Recently, Whiting and co-workers developed a catalytic protocol for the coupling of amino acids protected at the C- or Nterminus, with benzylamine or phenylacetic acid. ${ }^{72}$ It was shown that 3,4,5-trifluorophenylboronic acid, developed by Yamamoto 100 in 1996, and $o$-nitrophenylboronic acid were the most efficient catalysts in refluxing fluorobenzene (bp $85{ }^{\circ} \mathrm{C}$ ) using molecular sieves as water scavenger. The benzyl amide of Boc-protected proline was obtained in $90 \%$ isolated yield $(>99 \% e e)$ with Yamamoto's catalyst, whereas the o-nitrophenylboronic acid 105 catalyst furnished the benzyl amide of Boc-protected phenylalanine in $91 \%$ isolated yield $(79 \%$ ee $)$. Similarly, the amides from phenylacetic acid and the methyl ester hydrochlorides of phenylalanine and valine were obtained in $78 \%$ $(64 \%$ ee) and $68 \%$ ( $>99 \%$ ee) yields respectively, employing 110 Yamamoto's catalyst. The catalyst loading was $25 \mathrm{~mol} \%$ in all cases. The same arylboronic acids were also employed in the synthesis of dipeptides from two protected amino acids, resulting in yields of $20-62 \%$ with $100 \%$ catalyst loading at $65^{\circ} \mathrm{C}$. Lower catalyst loadings resulted in lower yields of the product. Although 115 this is a stoichiometric transformation, it represents the only example of linear dipeptides being formed with a boron-based 
mediator. In some cases, higher yields were obtained when the reaction was performed in the presence of two boronic acids (50 mol\% of each). The stereochemical purity of the starting materials was reported to be retained in the peptide products 5 (Scheme 18).

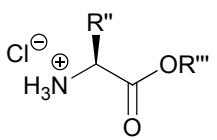

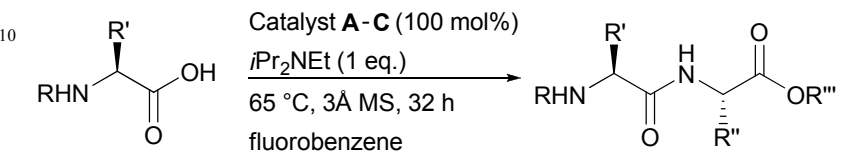<smiles>CCCCCCB(O)c1ccccc1C</smiles><smiles>COC(=O)C(Cc1ccccc1)NC(=O)C(Cc1ccccc1)NC(=O)OC(C)(C)C</smiles><smiles>CCOC(=O)CNC(=O)C(Cc1ccccc1)NC(=O)c1ccccc1</smiles>

$31 \%$, catalyst $\mathbf{A}$ $58 \%$, catalyst B

30<smiles>COC(=O)C(Cc1ccccc1)NC(=O)C(Cc1ccccc1)NC(C)C</smiles><smiles>COC(=O)C(Cc1ccccc1)NC(=O)C(Cc1ccccc1)NC(=O)c1ccccc1</smiles>

$48 \%$, catalyst B<smiles>COC(=O)[C@H](NC(=O)C(Cc1ccccc1)NC(C)C)C(C)C</smiles>

40

$$
\begin{aligned}
& 20 \%, \text { catalyst B } \\
& 51 \%, \text { catalyst B \& C }(50 / 50)
\end{aligned}
$$

$$
47 \% \text {, catalyst B }
$$

$62 \%$, catalyst B \& C $(50 / 50)$

Scheme 18. Selected dipeptides (Whiting, 2013).

All the boron-based catalysts described so far require elevated reaction temperatures in order to produce good yields of the amide product. However, in 2008, Hall and co-workers found that ortho-substituted phenylboronic acids, in particular $O$ 50 iodophenylboronic acid, were efficient catalysts at room temperature. $^{73}$ Although the protocol includes longer reaction times $(48 \mathrm{~h})$ and a higher dilution $(0.07 \mathrm{M})$ compared to earlier examples, a range of different amides with yields up to $90 \%$ were obtained at only $25{ }^{\circ} \mathrm{C}$ in THF or DCM. Importantly, the 55 conditions were mild enough to leave the labile stereocenter in enantiomerically pure (S)-ibuprofen essentially untouched $(<5 \%$ racemisation) in the reactions with benzylamine and $(R)-(+)-\alpha-$ methylbenzylamine (Scheme 19).
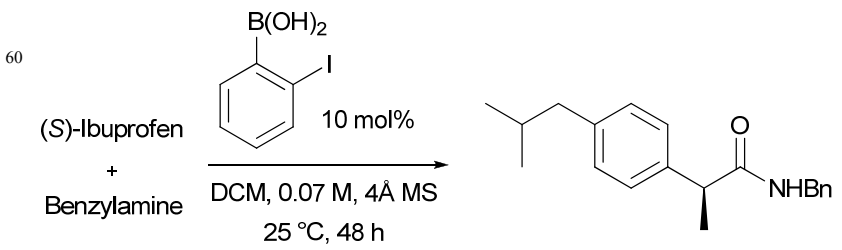

Yield $73 \%,<5 \%$ racemization

Scheme 19. Room-temperature amidation of (S)-Ibuprofen (Hall, 2008).

70 Mechanistic studies using DFT calculations suggested the involvement of acyl boronic species as intermediates for the catalytic activation of the carboxylic acids (Figure 5). ${ }^{74,75}$

75<smiles>[R]C(=O)OB([Al])OC([R])=O</smiles>

Figure 5. Proposed acylborate intermediates (Marcelli, 2010 and Guo, 2013)

Interestingly, kinetic and spectroscopic investigations revealed that an increased electron density of the iodo substituent by addition of a methoxy group in para position increased both the yield and reaction rate of the amidation (Scheme 20). ${ }^{76}$ 90<smiles>COc1ccc(I)c(Br)c1</smiles><smiles>[R]NC([R])=O</smiles>

Yield with catalyst (\%)

Product

Temp. $\left({ }^{\circ} \mathrm{C}\right)$ Time A

B

100
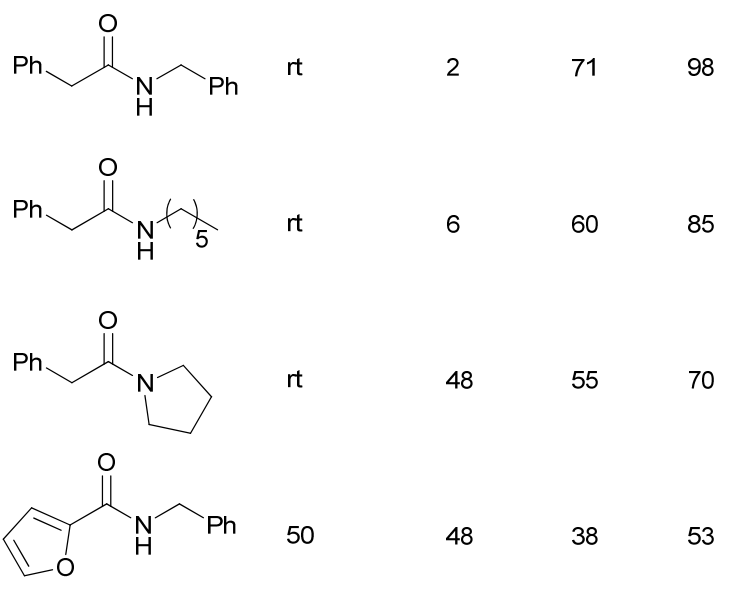

115 Scheme 20. Effect of the electronically modified $O$ iodophenylboronic acid catalyst in the amidation (Hall, 2012). 


\subsubsection{Kinetic resolution of amines}

In 2008, Whiting and co-workers published the first, and so far only, example of a kinetic resolution of amines using a chiral boronic acid catalyst in the amidation reaction with carboxylic 5 acids. ${ }^{77}$ The chiral catalyst, comprising a ferrocene backbone, gave an $e e$ of $41 \%$ (21\% yield) in the resolution of racemic 1phenylethylamine with benzoic acid in fluorobenzene. The chiral induction was less efficient for the resolution with 4phenylbutanoic acid (Scheme 21).

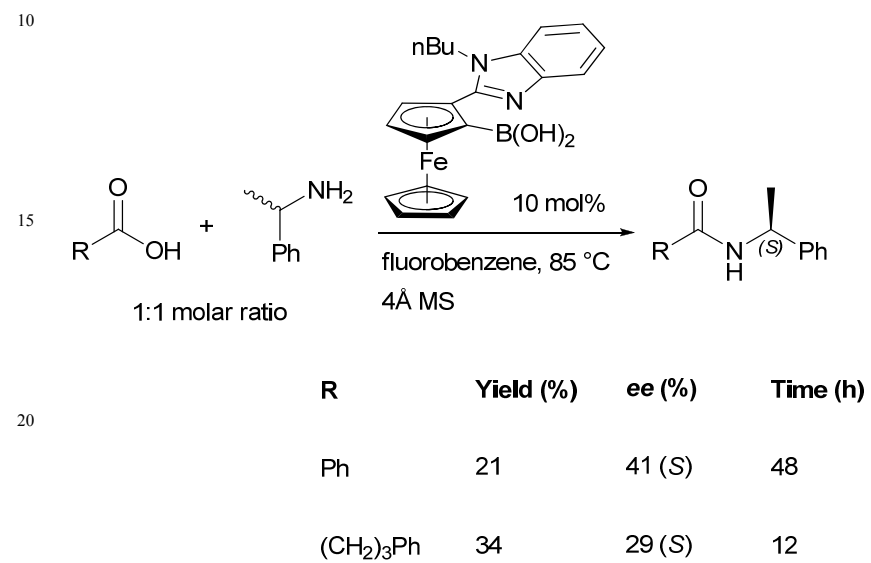

${ }_{25}$ Scheme 21. Kinetic resolution of primary amines by a chiral boron-based catalyst (Whiting, 2008).

\subsection{Recyclable boronic acid catalysts}

A polyfluorinated and recyclable boronic acid catalyst was developed by Yamamoto and co-workers. ${ }^{78}$ It was found that 3,530 bis(perfluorodecyl)phenylboronic acid (Figure 6) was the most active amidation catalyst in refluxing toluene by using molecular sieves in a Soxhlet thimble for the removal of water. When the reaction was performed in a fluorous biphasic system, the catalyst could be recovered by extraction with 35 perfluoromethylcyclohexane, and the fluorous phase could be reused. Alternatively, the catalyst, which becomes insoluble at room temperature, could be recycled by decantation of the product-containing layer. By employment of the latter recycling procedure, the catalyst was re-used ten times without any loss of 40 activity in the coupling of cyclohexanecarboxylic acid and benzylamine.<smiles>OB(O)c1cc(OC(F)(F)F)cc(C(F)(F)C(F)(F)F)c1</smiles>

Figure 6. A polyfluorinated boronic acid catalyst developed by Yamamoto and co-workers (2001).

50

The same group also reported on the use of cationic 4-borono- $\mathrm{N}$ methylpyridinium iodide as an efficient catalyst for the amide condensation in polar solvents. ${ }^{79}$ This finding was in parallel to similar catalysts from Wang and co-workers, who published the ${ }_{55}$ synthesis and use of 3-borono- $N$-methylpyridinium salt as well as an $N$-polystyrene resin-bound 3-boronopyridinium catalyst (Figure 7). ${ }^{80}$ With $1-5 \mathrm{~mol} \%$ of the immobilized catalyst, secondary and tertiary amides were formed in $87-98 \%$ yield. Lower yields were obtained when aniline or amines with a 60 boiling point lower than toluene were used. The authors demonstrated that the catalyst could be recycled at least three times without any loss of activity. However, the employed reaction conditions were found to completely racemise the stereocenters in the dipeptide of Cbz-protected phenylalanine and ${ }_{65}$ the tert-butyl ester of alanine.<smiles>CC[n+]1cccc(O)c1</smiles><smiles>[O-][18O]c1ccc[n+](Cc2ccc(O)cc2)c1</smiles>

Figure 7. 3-borono- $N$-alkylpyridinium salt catalysts developed by Wang and co-workers (2001).

${ }_{75}$ Furthermore, Yamamoto and co-workers demonstrated that the 4boronopyridinium catalysts showed a higher thermostability as compared to the 3-boronopyridinium analogues. ${ }^{81,82}$ The $N$ methylpyridinium boronic acids displayed an enhanced catalytic activity and could be recycled by the use of ionic liquids. ${ }_{80}$ Polystyrene-bound catalysts of the same type worked well in regular solvents and could be recycled by filtration (Figure 8).

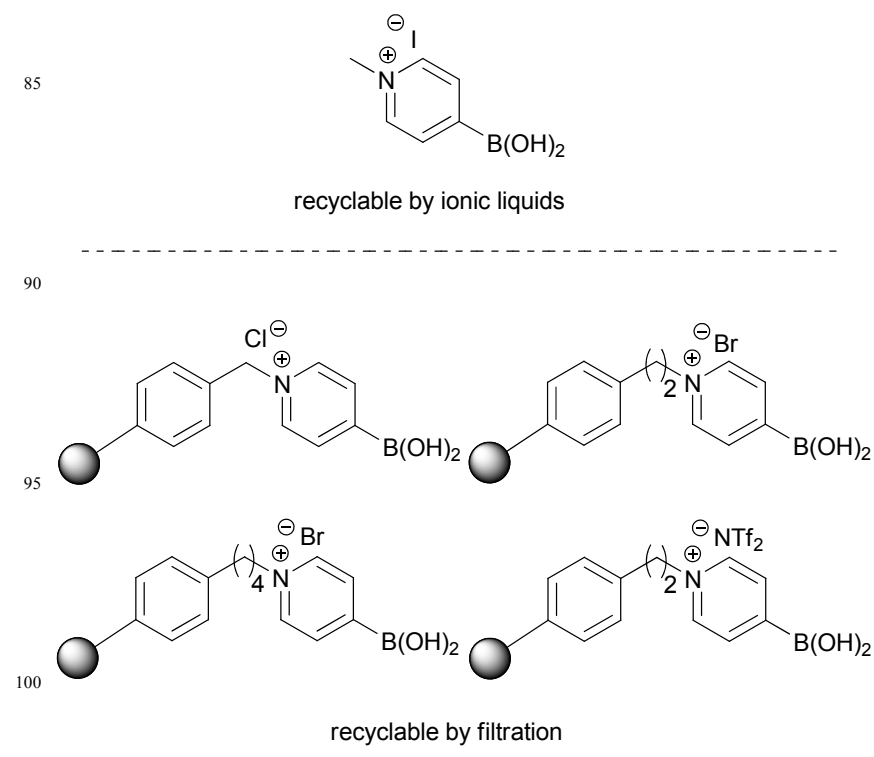

Figure 8. Recyclable boron-based catalysts (Yamamoto, 2005).

\section{4.3 Summary and conclusions on boron-based catalysts}

Boron-based catalysts generally work well with a fairly broad substrate scope, including hydroxy-substituted reactants. Boronic acids have also been demonstrated to be efficient catalysts for the synthesis of lactams by intramolecular direct amidation. The 110 yields are usually high and there are several examples where the catalyst can be recycled without loss of activity. The only example of a non-biological chiral catalyst for kinetic resolution of amines in the direct amidation is based on boron. ${ }^{77}$ A drawback for many of the boron-based catalysts is that they often require ${ }_{115}$ elevated reaction temperatures $\left(85^{\circ} \mathrm{C}\right.$ or more), which may result 
in problems with racemisation and limits the substrate scope. There are two notable exceptions of boronic acid catalysts that perform well at room temperature, thereby circumventing the racemisation issue. ${ }^{73}$ However, in this case, the reactant 5 concentrations must be low and a fairly large amount of molecular sieves is required to drive the reaction which limits large scale applications.

Although most boronic acids are stable towards water, its 10 removal is crucial to drive the reaction forward for the majority of the methods presented above, which might be troublesome for large-scale applications. Another challenge for the development of new boron-based catalysts includes the catalytic coupling of amino acids and peptides, which to date is limited to dimerization 15 or stoichiometric methods. The boron-based catalysts also seem to fail when it comes to the formation of primary amides. An exception is the protocol employing catalytic amounts of boric acid/PEG-400 which can be used to form the benzanilide of 4nitrobenzoic acid under rather harsh conditions. ${ }^{57}$

\section{${ }_{20}$ 5. Metal catalysis}

The use of metal-based catalysts for the direct amidation of carboxylic acids and amines has mainly received attention in the last few years, and remain an underdeveloped area. In general, oxophilic early transition metals are employed as catalysts, and

25 both homogenous and heterogeneous catalytic protocols are available.

\subsection{Homogeneous metal-catalysed protocols}

Group IV metals represent the dominant class of metal-based 30 catalysts employed for the direct amidation of non-activated carboxylic acids under homogeneous conditions. Nevertheless, other transition metals as well as main group metals have also found use as catalysts. In contrast to most other areas where metal-based catalysts are used, amidations are performed using 35 simple metal salts without incorporation of more sophisticated ligands than simple counter ions (i.e. halides, alkoxides or acetates). Therefore, one can foresee that more developed metal complexes, containing ligands with a tuning ability, will be evaluated as amidation catalysts in the future.

\subsubsection{Primary amides}

The metal-catalysed formation of primary amides from carboxylic acids and ammonia is less explored than the synthesis of secondary or tertiary amides. The first report was published by ${ }_{45}$ Shteinberg in 2003 , who used $\mathrm{Ti}(\mathrm{OBu})_{4}$ in combination with PEG-400 for the reaction of 4-nitrobenzoic acid and ammonia. ${ }^{57}$ The amide was formed in $90 \%$ yield using $2 \mathrm{~mol} \%$ of the titanium complex and $0.9 \mathrm{~mol} \%$ PEG-400 in refluxing trichlorobenzene (Scheme 22). Neither $\mathrm{Ti}(\mathrm{OBu})_{4}$ nor PEG-400 50 were active as catalysts on their own.

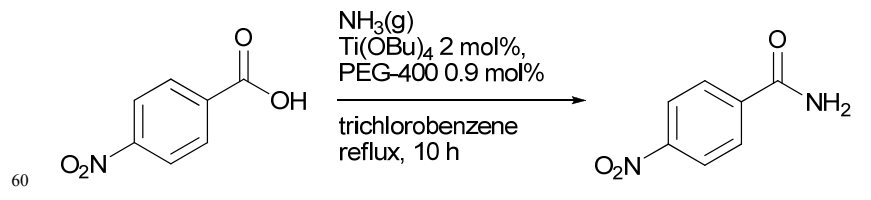

Scheme 22. Titanium-catalysed formation of 4-nitrobenzanilide (Shteinberg, 2003).

65 In 2012, Adolfsson and co-workers reported that the tetrachloride complexes of titanium and zirconium catalysed the formation of primary amides, using ammonium carbamate as the source of ammonia. ${ }^{83}$ Although a higher catalyst loading was employed, compared to Shteinberg's protocol, the reaction was 70 performed at a lower reaction temperature. Nine primary amides were formed in $67-99 \%$ yield, using $20 \mathrm{~mol} \%$ of the catalyst at $100-120^{\circ} \mathrm{C}$ in the presence of molecular sieves. The authors also showed that $\mathrm{N}, \mathrm{N}$-dimethylammonium $\mathrm{N}, \mathrm{N}$-dimethylcarbamate worked well as a source of dimethylamine to afford nine different 75 dimethylamides in $61-99 \%$ yield under similar reaction conditions (Scheme 23). The thermal amidation reaction, in the absence of catalyst, furnished the primary amides and dimethyl amides in $2-14 \%$ and $5-17 \%$ yield, respectively.

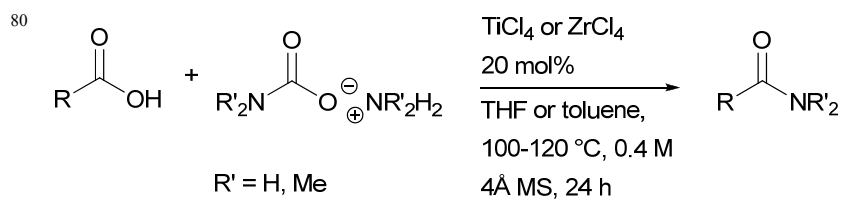

Scheme 23. Formation of primary and tertiary amides using carbamates as amine sources (Adolfsson, 2012).

\subsubsection{Secondary and tertiary amides}

90 The use of metal complexes as Lewis acidic mediators for the formation of secondary and tertiary amides goes back to the 1970's, when Wilson and Weingardten used stoichiometric amounts of $\mathrm{TiCl}_{4}$ to form carboxamides from non-activated carboxylic acids and amines. ${ }^{84}$ In 1972, the first patent was filed 95 for a catalytic process describing the production of amides from different long chain fatty acids and amines. ${ }^{85}$ The authors used 0.6-1 mol\% of metal complexes based on $\mathrm{Ti}(\mathrm{IV}), \mathrm{Zr}(\mathrm{IV})$ and $\mathrm{Ta}(\mathrm{V})$ as catalysts, with reaction temperatures of $120-200^{\circ} \mathrm{C}$, and reached near-quantitative yields in a couple of hours of reaction 100 time. In 1979, another patent was filed for the catalytic production of $\mathrm{N}, \mathrm{N}$-dimethyl-m-toluamide from the corresponding carboxylic acid and amine. ${ }^{86}$ At elevated reaction temperatures (150-300 $\left.{ }^{\circ} \mathrm{C}\right)$, the amide was formed from a mixture with $2: 1$ molar ratio of carboxylic acid to amine with typically $0.2-0.5$ $105 \mathrm{~mol} \%$ of different $\mathrm{Ti}(\mathrm{IV})$-complexes as catalysts with the removal of water.

In the beginning of the 1980's, Steliou et al. reported on the formation of five- to seven-membered lactams in near 110 quantitative yield (95\%) with $10 \mathrm{~mol} \% \mathrm{Bu}_{2} \mathrm{SnO}$ in refluxing xylene and a Dean-Stark trap for the removal of water (Scheme 24) ${ }^{87,88}$ Although the method failed for the synthesis of $\beta$-lactams 
and macrocyclic lactams, one example of a bridged lactam was reported with the use of a stoichiometric amount of the tin complex.

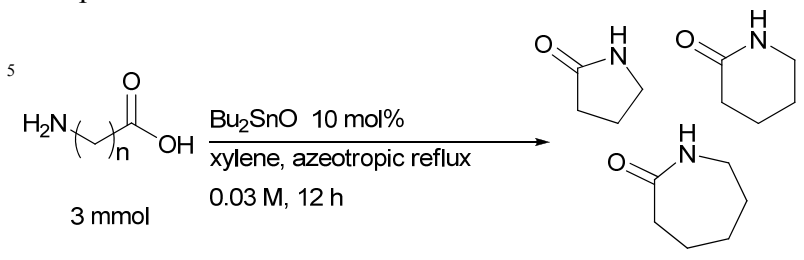

$95 \%$ yield

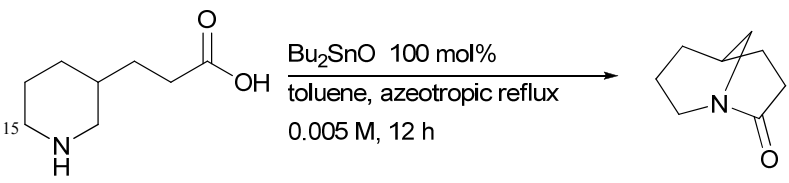

$0.63 \mathrm{mmol}$

$77 \%$ yield

Scheme 24. Tin-catalysed/mediated lactamisation reactions (Steliou, 1983).

In 1988, Mader and Helquist reported on the lactamisation of linear amino acids using $50 \mathrm{~mol} \%$ of $\mathrm{Ti}\left(\mathrm{O}^{i} \mathrm{Pr}\right)_{4}$ in refluxing dichloroethane $\left(\mathrm{bp} 83{ }^{\circ} \mathrm{C}\right){ }^{89}$ The lactams were obtained in 35 $93 \%$ yield with a ring size of 5-7 atoms (Scheme 25 ). When the 25 catalyst loading was reduced to $10-25 \mathrm{~mol} \%$, lower yields of the lactams were observed. Moreover, the method failed for the formation of linear amides.

30<smiles>CC1CCNC1=O</smiles>

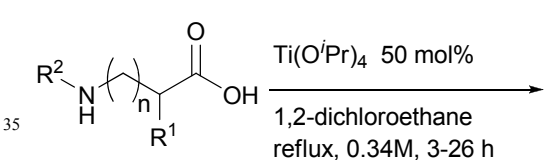<smiles>CN1CCCC1=O</smiles>

$81 \%$<smiles>O=C1CCCN1</smiles><smiles>CN1CCCCC1=O</smiles>

$86 \%$
$75 \%$

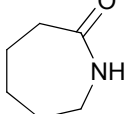

$35 \%$
Scheme 25. $\mathrm{Ti}\left(\mathrm{O}^{i} \mathrm{Pr}\right)_{4}$-catalysed lactamisations (Helquist, 1988).

The first catalytic intermolecular amidation protocol was ${ }_{45}$ published by Shteinberg et al., employing $\mathrm{Ti}(\mathrm{OBu})_{4}$ as a catalyst for the acylation of aniline with various carboxylic acids. ${ }^{90}$ By the use of a $2 \mathrm{~mol} \%$ catalyst loading in refluxing o-xylene (bp 145 ${ }^{\circ} \mathrm{C}$ ), the authors showed that the titanium butoxide complex was a superior catalyst, $85 \%$ yield compared to $\mathrm{TiCl}_{4}(39 \%), \mathrm{SnCl}_{4}$ $50(26 \%), \mathrm{Bu}_{2} \mathrm{SnO}(22 \%)$ and $\mathrm{BF}_{3} \cdot \mathrm{OEt}_{2}(10 \%)$ in the amidation of benzoic acid and aniline. The efficacy of the $\mathrm{Ti}(\mathrm{OBu})_{4}$ catalyst was demonstrated in 21 examples where the amide yields ranged from 38 to $98 \%$ with a thermal reaction contributing to $0-5 \%$. Lower yields were obtained with di-carboxylic acids, and a free ${ }_{55}$ hydroxyl group in the para-position of the benzoic acid substrate was found to inhibit the reaction. However, the authors found that $2 \mathrm{~mol} \%$ of the titanium complex catalysed the formation of the anilide product 3-hydroxy-2-naphthoic acid in $80 \%$ yield, when the substrate was refluxed in aniline (bp $184^{\circ} \mathrm{C}$ ) for two hours. ${ }^{91}$ ${ }_{60}$ Furthermore, it was demonstrated that substituted anilines were effective as coupling partners with benzoic acid under the same reaction conditions. ${ }^{92}$ Anilines substituted with electron donating groups were generally giving rise to higher conversions than electron poor anilines, with the exception of aminophenols, where ${ }_{65}$ the OH-group seemed to retard the reaction. Selected examples are given in Figure 9.<smiles>COc1ccccc1C(=O)Nc1ccccc1C(=O)Nc1ccccc1</smiles><smiles>COc1cccc(C(=O)Nc2ccccc2)c1</smiles><smiles>COc1ccc(C(=O)Nc2ccccc2)cc1</smiles><smiles>COc1ccc(NC(=O)c2ccccc2)cc1</smiles>

Figure 9. Selected examples for the $\mathrm{Ti}(\mathrm{OBu})_{4}$-catalysed amidation of benzoic acids and anilines (Shteinberg, 1988 and 95 1989).

The amidation of benzoic acid with aniline performed optimal in non-polar aprotic media under an azeotropic removal of water. In the presence of polar solvents such as DMF, DMSO, HMPA and 100 sulfolane, the amidation reaction was inhibited even at $10 \mathrm{~mol} \%$ concentration in $o$-xylene. ${ }^{93}$

Shteinberg et al. observed that batches of the $\mathrm{Ti}(\mathrm{OBu})_{4}$ catalyst which had been standing on the shelf for some time seemed to 105 perform better than freshly distilled ones. The authors attributed this effect to the involvement of water at some stage in the reaction and therefore investigated the catalytic activity of aged batches of the catalyst. ${ }^{94}$ Reproducible results were obtained when the aging of the catalyst was performed under controlled 110 conditions in a moist cell. ${ }^{95}$ The most active catalyst was obtained after 5.5 hours of aging, with an estimated absorption of about 1.8 mol-equivalents of water. A yield of $45 \%$ was observed in the formation of benzanilide using the aged catalyst, whereas freshly distilled catalyst furnished the same product in only $15 \%$ yield 15 under otherwise identical reaction conditions. It was suggested that the water hydrolyses the butoxide ligands of the catalyst to 
form linear oligomers of polytitanate which were assumed to be the most active form of the catalyst. A higher degree of water absorption led to a lower catalyst activity which was explained by a cross-linking of the linear oligomers that are less soluble in the 5 reaction medium. Alternatively, the activation of the catalyst could be performed by pre-treating the catalyst with benzoic acid prior to the reaction. ${ }^{96}$ The reaction progress of the amidation was also found to be highly dependent on a high mass transfer rate of water. $^{97}$

The $\mathrm{N}$-formylation of amines using neat formic acid and zinc(II) chloride as catalyst was investigated by Shekhar et al. ${ }^{98,99}$ Electron rich aniline derivatives were reported to be highly reactive, furnishing the formamide products in $80-98 \%$ yield after

15 10-90 min at $70^{\circ} \mathrm{C}$ using $10 \mathrm{~mol} \%$ of $\mathrm{ZnCl}_{2}$ (Scheme 26). Electron-poor aryl amines and secondary amines however, required longer reaction times (4-15h) in order to obtain useful yields. Other Lewis acidic metal salts such as $\mathrm{SnCl}_{2}, \mathrm{LaCl}_{3}$ and $\mathrm{La}(\mathrm{OTf})_{3}$ were equally efficient as catalysts for the synthesis of 20 formanilide ( $>90 \%$ yield in all cases). In absence of a catalyst, the reaction did not proceed. Moreover, the amidation of longer chain carboxylic acids with aniline was less effective under the reported reaction conditions; when acetic acid was used, the amide was formed in 55\% yield after 12 hours while decanoic acid remained 25 unreacted.

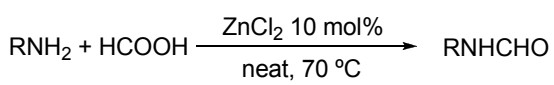<smiles>O=CNc1ccccc1</smiles>

$96 \%, 10 \mathrm{~min}$<smiles>O=CNc1ncccn1</smiles>

$96 \%, 30 \mathrm{~min}$<smiles>O=CN1CCOCC1</smiles>

$80 \%, 240 \mathrm{~min}$

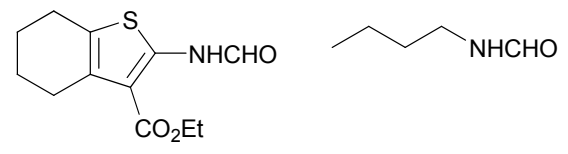

$$
95 \%, 200 \mathrm{~min} \quad 60 \%, 60 \mathrm{~min}
$$

Scheme 26. $\mathrm{ZnCl}_{2}$ catalysed $\mathrm{N}$-formylation (Shekhar, 2009).

Another method for the catalytic $N$-formylation of anilines 45 with formic acid was published by Azizi et al. ${ }^{100}$ Tin(II) chloride was used as catalyst in the form of a deep eutectic solvent $(D E S)^{101}$ for the formylation of a series of anilines. The formanilide products were obtained in up to excellent yields using $30 \mathrm{~mol} \%$ of the tin(II) chloride-choline chloride DES ${ }_{50}$ catalyst at $70{ }^{\circ} \mathrm{C}$. Formic acid was found to be a superior formylating reagent compared to trimethyl orthoformate.

Williams and co-workers reported on the thermal amidation of carboxylic acids and amines, which was found to take place to a ${ }_{55}$ fairly high extent at $110{ }^{\circ} \mathrm{C}$ in toluene. ${ }^{13}$ In the reaction of 3phenylpropionic acid and 4-methylbenzylamine, the corresponding amide was formed in $20 \%$ yield after 4 hours, and a full conversion was obtained after 20 hours in the absence of a catalyst. However, the authors found that the reaction rate was ${ }_{60}$ dramatically increased by the addition of various metal complexes in catalytic amounts. The most efficient catalysts were identified as $\mathrm{ZrCl}_{4}$ and $\mathrm{ZrCp}_{2} \mathrm{Cl}_{2}$, which led to high conversions after four hours of reaction time using a $5 \mathrm{~mol} \%$ catalyst loading (Scheme 27). The yields of the catalysed reactions were in almost ${ }_{65}$ all cases higher than for the thermal reactions of the same substrates. The pharmaceuticals paracetamol and moclobemide were synthesized with full conversion using zirconium catalysis, as compared to $37 \%$ and $14 \%$ yield of the thermal reaction, respectively. The benzyl amide of $N$-Boc-proline was also formed 70 in a moderate isolated yield of $56 \%$, and with retained stereochemical purity. The thermal reaction for this substrate was found to be non-existing at $100{ }^{\circ} \mathrm{C}$.

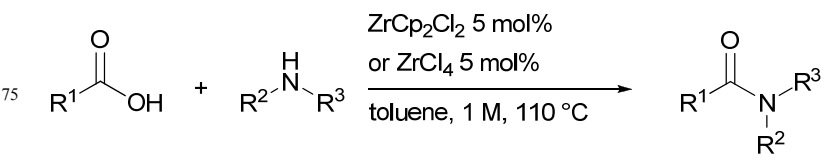<smiles>Cc1ccc(CNC(=O)CCc2ccccc2)cc1</smiles><smiles>O=C(CCc1ccccc1)NCCCCO</smiles><smiles>O=C(CCc1ccccc1)N1CCOCC1</smiles><smiles>CC(C)(C)OC(=O)NCC(=O)NCc1ccccc1</smiles>

$80 \%, 22 \mathrm{~h}$<smiles>CCC(=O)NCc1ccccc1</smiles><smiles>O=C(NCc1ccccc1)C1CCCN1C(=O)OCc1ccccc1</smiles>

$56 \%, 22 \mathrm{~h}$

$>99 \%$ ee

${ }_{95}$ Scheme 27. Selected examples of amides formed by Williams' catalytic protocol (2012).

Simultaneously, and in parallel to the work of Williams, Adolfsson and co-workers reported that $\mathrm{ZrCl}_{4}$ worked well as 100 catalyst at $70{ }^{\circ} \mathrm{C}$ in THF when molecular sieves were present as a water scavenger. ${ }^{14}$ The authors found that the thermal background reaction at $70{ }^{\circ} \mathrm{C}$ was considerably lower than that taking place at $110{ }^{\circ} \mathrm{C}$, which was reported by Williams. For phenylacetic acid, the corresponding benzylamide was formed in $10510-13 \%$ yield after 24 hours, depending on the acid to amine ratio. The authors reported 24 examples of secondary and tertiary amides being formed in $62-99 \%$ yield with a $2-10 \mathrm{~mol} \%$ catalyst loading (Scheme 28). No racemisation of the stereocenter in Bocprotected alanine and proline was detected in the coupling with 110 benzylamine, nor for the amide resulting from the coupling of (R)-1-phenylethylamine with phenylacetic acid. Furthermore, the benzylamide of the anti-inflammatory drug indomethacin was formed in $97 \%$ isolated yield employing $2 \mathrm{~mol} \%$ of $\mathrm{ZrCl}_{4}$. The zirconium-catalysed amidation reaction was found to be suitable 115 for larger scale syntheses; a comparable yield for $\mathrm{N}$-benzyl-2phenylacetamide was obtained on a $40 \mathrm{mmol}$ scale. 


$$
\text { (1) }
$$

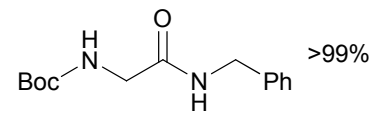

Scheme 28. Zirconium-catalysed amidation, selected examples 20 (Adolfsson, 2012).

The authors also demonstrated the efficacy of $\mathrm{Ti}(\mathrm{OiPr})_{4}$ as catalyst in the amidation reaction. A range of amides was obtained using a $10 \mathrm{~mol} \%$ loading at $70{ }^{\circ} \mathrm{C}$ with $4 \AA$ molecular ${ }_{25}$ sieves as water scavenger. ${ }^{102}$ These results were in contrast to the early work of Helquist and Mader who observed no product for the intermolecular amide formation with the same catalyst. ${ }^{89}$

Terada et al. reported on the catalytic activity of metal salts in 30 the amidation of long-chain aliphatic carboxylic acids and amines in refluxing mesitylene (bp $163{ }^{\circ} \mathrm{C}$ ). ${ }^{103}$ Several metal chloride complexes were examined, and it was found that $\mathrm{FeCl}_{3} \cdot 6 \mathrm{H}_{2} \mathrm{O}$ was the most efficient catalyst, followed by $\mathrm{ZnCl}_{2}, \mathrm{NiCl}_{2} \cdot 6 \mathrm{H}_{2} \mathrm{O}$ and $\mathrm{MnCl}_{3} \cdot 6 \mathrm{H}_{2} \mathrm{O}$. The reaction worked best in high boiling solvents 35 at refluxing conditions with a Dean-Stark apparatus for the azeotropic removal of water. The aliphatic amides were formed in $47-93 \%$ yield after 6 hours using $2 \mathrm{~mol} \%$ of $\mathrm{FeCl}_{3} \cdot 6 \mathrm{H}_{2} \mathrm{O}$ as catalyst (Figure 10). In contrast to many other metal and enzyme catalysts, the reaction was only effective with carboxylic acids as 40 substrates; the aminolysis of methyl palmitate with decylamine did not occur under the applied reaction conditions.

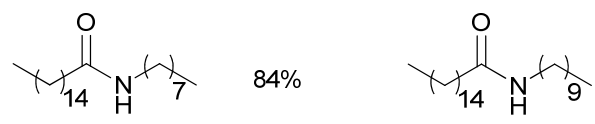

$81 \%$

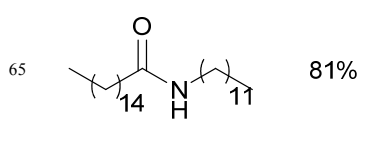

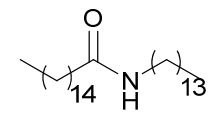<smiles>CCCCCC</smiles>

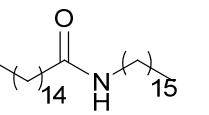

$62 \%$

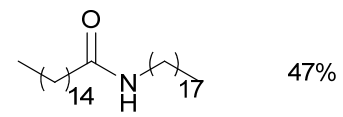

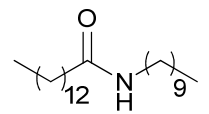

$92 \%$

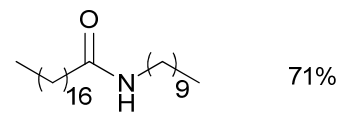

75

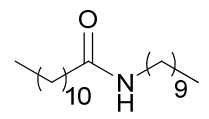

$90 \%$

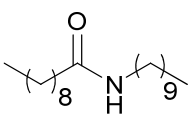

$47 \%$

Figure 10. Substrate scope for the $\mathrm{FeCl}_{3}$-catalysed synthesis of aliphatic amides (Terada, 2008).

85

Brahmachari et al. found that zinc acetate worked well as catalyst for the acetylation of amines in acetic acid under reflux (with 25-30 mol\% catalyst loading), and under microwave irradiation (with $0.9 \mathrm{~mol} \%$ loading and $300 \mathrm{~W}) .^{104,105}$ Primary 90 and secondary amines, both aromatic and aliphatic ones, were acetylated in good to excellent yields. The reaction was found to be highly selective for $N$-acetylation in the presence of other nucleophiles such as alcohols and thiols. Furthermore, it was demonstrated that the acetylation of amines worked well with the 95 acetate complexes of sodium, calcium, magnesium, manganese and copper as catalysts. The authors discovered that the $\mathrm{N}$ acetylation also worked well when $\mathrm{Zn}(\mathrm{OAc})_{2}$ was used in a stoichiometric amount in the absence of acetic acid. An analysis of the residual metal showed that $\mathrm{ZnO}$ had formed during the 100 reaction. Since the metal acetate could be recovered after the catalysis in acetic acid, it was presumed that the metal oxide could be used as pre-catalyst to form the metal acetate in situ. This assumption proved to be correct and the authors demonstrated that $\mathrm{ZnO}, \mathrm{Cr}_{2} \mathrm{O}_{3}, \mathrm{Al}_{2} \mathrm{O}_{3}, \mathrm{CaO}$ and $\mathrm{MgO}$ could be 105 used as pre-catalysts in the acetylation reaction.

A reusable homogenous catalyst system was developed by De Oliveira et al. A variety of amides were formed in $82-97 \%$ yield from fatty acids and pyrrolidine with $5 \mathrm{~mol} \%$ of $\mathrm{CdO}$ or $\mathrm{SnCl}_{2}$

110 using an ionic liquid (1-n-butyl-3-methylimidazolium bis(trifluoromethylsulfonyl)imide) as reaction medium. ${ }^{106}$ The metal catalysts could be reused up to 8 times by recycling of the ionic liquid after decantation and extraction of the amide products. In addition, $\mathrm{Sb}(\mathrm{OEt})_{3}$ was mentioned by Yamamoto and 115 co-workers to be catalytically active for the amidation of a handful of substrates. ${ }^{107}$ 


\subsection{Heterogeneous metal-containing catalysts}

The main advantage of heterogeneous catalysis is the possibility of facile separation of the catalyst from the reaction medium and the potential recyclability, overall leading to a better atom 5 economy. The development of heterogeneous catalysts for the direct amidation of carboxylic acids started already in the 1970's and originates largely from origin of life experiments, studying the formation of peptides from amino acids aided by minerals and clays. The proposed models used different techniques in attempts 10 to mimic the primitive earth, and the general idea was that amino acids were adsorbed to the mineral surface to form active esters for further condensation. In the synthetic protocols investigating this hypothesis, the yields of peptides were in general in the order of a few percent and the reaction times were measured in days to 15 months. For this reason, the literature in this field is not covered by this review but can be found elsewhere. ${ }^{108}$ The catalytic formation of peptides from non-activated amino acids is not an easy task, and to date there are no general catalytic methods for this transformation, neither homogeneous nor heterogeneous. 20 However, several heterogeneous catalytic protocols for direct amidation of other types of carboxylic acids and amines have been developed. Little is known about the operating mechanisms of the heterogeneous catalysts. Hence, this section covers all catalytic protocols which contain metal ions, without speculations

25 on whether the catalytic effect is due to the incorporated metal or not.

\subsubsection{Synthesis of primary amides}

Only a few heterogeneous metal-catalysed syntheses of primary 30 amides have been reported in the literature. Reddy et al. published a $\mathrm{ZrOCl}_{2} \cdot 8 \mathrm{H}_{2} \mathrm{O}$-catalysed amidation protocol under microwave irradiation $\left(80{ }^{\circ} \mathrm{C}, 100 \mathrm{~W}\right)$ for the formation of primary amides from 25 different carboxylic acids using urea as nitrogen source. ${ }^{109}$ The authors reported yields of $73-94 \%$ in only 35 20-80 seconds of reaction time under solvent-free conditions. Furthermore, the catalyst could be recycled up to three times without loss of activity. The authors also reported that $2 \mathrm{~mol} \%$ of cerium ammonium nitrate (CAN) could be employed as catalyst for the same reaction under similar conditions. ${ }^{110}$ The thermal 40 yields of the two reactions were reported to be non-existent. It should be noted that the two protocols have been reported to be difficult to reproduce. ${ }^{83}$

\subsubsection{Secondary and tertiary amides}

${ }_{45}$ Zeolites, a heterogeneous aluminosilicate-based material with a microporous structure, have been employed as catalysts in the direct amidation of non-activated carboxylic acids. In 1998, Gadhwal et al. published the first catalytic protocol based on the protonated form of zeolite Y (zeolite-HY) as heterogeneous ${ }_{50}$ catalyst for direct amidation reaction. ${ }^{111}$ The reactions were performed in a domestic microwave oven under solvent free conditions for 30-60 min to obtain the secondary amide products in $80-97 \%$ yield. The loading of the zeolite-HY catalyst was 50 $\mathrm{mg} / \mathrm{mmol}$ substrate with an equimolar amount of the carboxylic ${ }_{55}$ acid and amine substrates. When the reaction of aniline and acetic acid was performed in the absence of microwave irradiation, the amide product was obtained in $25 \%$ yield. However, no experimental details were given for this control experiment or for the microwave method.

60

The catalytic activity of zeolite-HY in the acylation of amines was further investigated by Kulkarni and co-workers. ${ }^{112}$ The reaction was performed in refluxing acetic acid with a catalyst loading of $150 \mathrm{mg} / \mathrm{mmol}$ substrate for the synthesis of aromatic 65 as well as aliphatic acetamides (Scheme 29). The chemoselectivity of the catalytic amidation was demonstrated in the reaction of 4-hydroxyaniline where only $N$-acetylation was observed. Furthermore, the ester functionality in phenylalanine methyl ester remained untouched under the reaction conditions, 70 which is in contrast to many other amidation catalysts which are also active catalysts for aminolysis of esters. The thermal reaction was found to be slow in the control experiment with benzylamine, and the zeolite-HY catalyst could be recycled three times without any loss of activity.

75

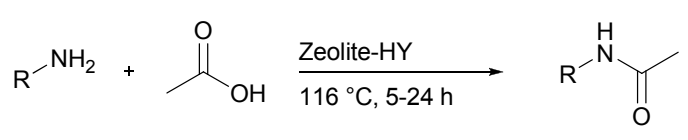

80

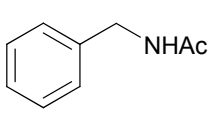

$99 \%, 5 \mathrm{~h}$<smiles>CCNc1ccccn1</smiles>

$85 \%, 24 \mathrm{~h}$<smiles>CC(=O)NC(Cc1ccccc1)C(C)=O</smiles>

$98 \%, 8 \mathrm{~h}$

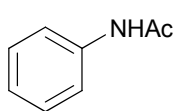

$99 \%, 6 \mathrm{~h}$<smiles>CC(=O)Nc1ccccc1C#N</smiles>

$10 \%, 8 \mathrm{~h}$<smiles>CCNc1ccc(Cl)cc1</smiles>

$99 \%, 6 \mathrm{~h}$<smiles>CCNC1CCCCC1</smiles>

$98 \%, 8 \mathrm{~h}$
${ }_{95}$ Scheme 29. Zeolite-HY -catalysed acylation of aromatic and aliphatic amines (Kulkarni, 2000).

The catalytic acetylation of amines was further investigated by employing metal doped zeolites under microwave irradiation. It 100 was found that an iron doped zeolite (Feß-zeolite) was the most efficient catalyst in comparison to zeolites containing $\mathrm{La}, \mathrm{Cu}, \mathrm{Cr}$, $\mathrm{Co}, \mathrm{Zn}, \mathrm{Ni}, \mathrm{Pb}$, and $\mathrm{W}$. The iron doped catalyst could be recycled at least three times without any loss in activity. ${ }^{113}$

105 Recently, Bahari et al. published a protocol for the direct $\mathrm{N}$ formylation of amines using a natural HEU zeolite as a recyclable catalyst. ${ }^{114}$ The reaction could be performed under very mild conditions (ambient temperature) in short reaction times and the catalyst could be recycled five times with a minimal loss in yield. 110 In order to expand the substrate scope for zeolite catalysts to include bulkier substrates, Sugi and co-workers developed a material with a larger pore size. ${ }^{115}$ A calcium-containing mesoporous aluminosilicate molecular sieves (AlMMSH) catalyst was employed for the condensation of fatty acids and long-chain 
aliphatic amines. The reaction of palmitic acid and $\mathrm{N}$ hexadecylamine furnished the aliphatic amide in $69 \%$ conversion at elevated temperatures $\left(150^{\circ} \mathrm{C}\right)$.

5 The first catalytic protocol employing formic acid as formylating reagent was developed by Hosseini-Sarvari and coworkers in 2006. ${ }^{116}$ It was demonstrated that the $\mathrm{N}$-formylation of both aromatic and aliphatic amines could be performed at $70^{\circ} \mathrm{C}$ under solvent-free conditions using $\mathrm{ZnO}$ as catalyst. The

10 formamide products were obtained in good to excellent yields in reaction times of 10-720 minutes (Figure 11).

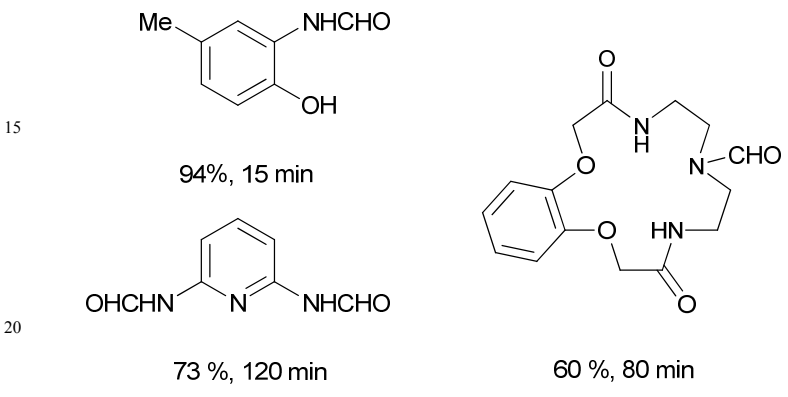

Figure 11. Selected examples from the first $N$-formylation of amines with formic acid using $\mathrm{ZnO}$ as catalyst (Hosseini-Sarvari, 25 2006).

During the optimization studies, it was noted that the amount of formic acid was crucial; a large excess of formic acid gave only trace amounts of the desired product. The optimal ratio (formic 30 acid:amine) was found to be 3:1, furnishing a $99 \%$ yield of the model product formanilide using a catalyst loading of $50 \mathrm{~mol} \%$. If the catalyst loading was either increased or decreased from the optimal $50 \mathrm{~mol} \%$, this also resulted in a lower yield. The catalyst could be recovered and reused, although with a small loss of the 35 catalyst for each run (4-10\%). Furthermore, the catalytic protocol was suitable for a large-scale synthesis, demonstrated by the formylation of aniline on a $100 \mathrm{mmol}$ scale with a yield of $99 \%$ after $40 \mathrm{~min}$.

40 In 2007, Thakuria et al. performed a comparative study, ${ }^{117}$ using macroporous $\mathrm{ZnO}$ and other macroporous metal oxides $\left(\mathrm{CuO}, \mathrm{NiO}, \mathrm{CoO}, \mathrm{Mn}_{2} \mathrm{O}_{3}\right.$ and $\left.\mathrm{Cr}_{2} \mathrm{O}_{3}\right)$ as catalysts in the $\mathrm{N}$ formylation under conditions similar to those present in the Hosseini-Sarvari protocol. It was shown that the recyclable 45 macroporous metal-oxide catalysts could be used in significantly lower loadings $(0.05 \%-0.25 \%)$ compared to the amorphous compounds, still giving rise to comparable yields. The authors suggested that this improvement was due to the larger internal surface area and pore volume of the macroporous material.

50

Recently, other research groups have continued to explore zinc oxide as catalyst for direct amidation of carboxylic acids. Tamaddon et al. prepared a $\mathrm{ZnO}$-nanofluid by dispersing $\mathrm{ZnO}$ nanoparticles in glycerol. ${ }^{118}$ The authors reported that the $\mathrm{ZnO}$ -

55 nanofluid was a more efficient catalyst than the zinc nanoparticles itself, suggesting better diffusion and dispersion abilities of the nanofluid catalyst in the reaction mixture. A series of amides were prepared under neat conditions at $110^{\circ} \mathrm{C}$, with a catalyst loading of $160 \mathrm{mg} \mathrm{ZnO}$ nanofluid to $1 \mathrm{mmol}$ substrate 60 (50 $\mathrm{wt} \% \mathrm{ZnO}$ in the catalyst). A representative example of the efficiency of the protocol was illustrated by the reaction of stearic acid and aniline, which furnished $N$-phenylstearamide in $91 \%$ yield after 4 hours. However, the thermal reaction was found to contribute substantially to the yield (56\%) under the applied ${ }_{65}$ reaction conditions. The reaction was found to be accelerated under microwave irradiation, yielding the amide products in short reaction times (60-180 seconds). The $\mathrm{ZnO}$-nanofluid in itself was not recovered after the reaction, although the $\mathrm{ZnO}$ nanoparticles could be recovered and dispersed again in glycerol without any 70 loss in catalytic activity after three consecutive cycles.

Other metal oxides have also attracted attention in recent years. Reddy et al. prepared a porous nanocrystalline- $\mathrm{MgO}$ material by calcination of a mixture of $\mathrm{Mg}\left(\mathrm{NO}_{3}\right)_{2} \cdot 6 \mathrm{H}_{2} \mathrm{O}$ and 75 glycine. ${ }^{119}$ The nano-MgO was utilized as catalyst for the $\mathrm{N}$ formylation of anilines under microwave irradiation $(320 \mathrm{~W})$ to obtain the corresponding formanilides in $90-98 \%$ yield after $1-2$ minutes (Scheme 30). The background reaction showed only traces of the formylated amine and a comparative study with 80 commercially available bulk-MgO showed that the catalytic power of nano- $\mathrm{MgO}$ was superior.
85

$\begin{array}{ll} & \mathbf{R} \\ & \mathrm{H} \\ & 4-\mathrm{Me} \\ & 4-\mathrm{MeO} \\ & 4-\mathrm{NO}_{2} \\ & 2-\mathrm{OH}\end{array}$

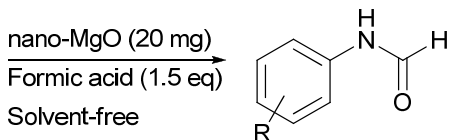

Time (s) Yield (\%)

$60 \quad 98$

$80 \quad 98$

$100 \quad 92$

$60 \quad 97$

8590
Scheme 30. Microwave-assisted formylation of anilines with a 95 nano-MgO catalyst (Reddy, 2010).

The group of Hosseini-Sarvari recently reported on a nanosulfated $\mathrm{TiO}_{2}$ catalyst for the direct amidation of fatty acids. ${ }^{120}$ It was found that a $98 \%$ yield could be obtained in the reaction of 100 stearic acid and aniline after $3 \mathrm{~h}$ using $0.011 \mathrm{~mol} \%$ of the catalyst at $115{ }^{\circ} \mathrm{C}$. The procedure worked well for variety of aromatic, heteroaromatic, aliphatic and long chain amines in the condensation with stearic acid under solvent free conditions (Scheme 31). Additionally, a few benzoic acid derivatives were 105 shown to form the secondary amides with aniline in excellent yields, employing the same titania catalyst. Performing the reaction in absence of the titania catalyst did not show any trace of the amide, even after 48 hours. Although this direct amidation protocol was based on a heterogeneous catalyst, no recycling 110 study was reported. 


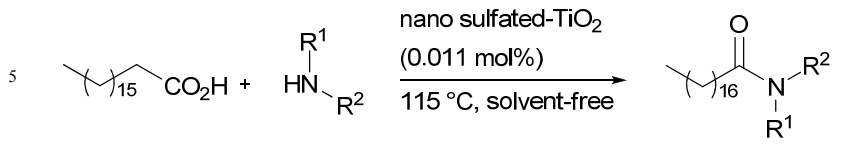

10<smiles>CCCCCCC(=O)Nc1ccccc1</smiles>

$98 \%, 3 \mathrm{~h}$

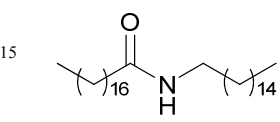

$98 \%, 2.5 \mathrm{~h}$

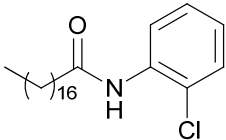

$98 \%, 6 \mathrm{~h}$

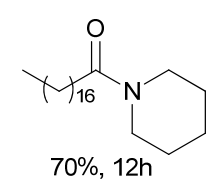

$70 \%, 12 \mathrm{~h}$

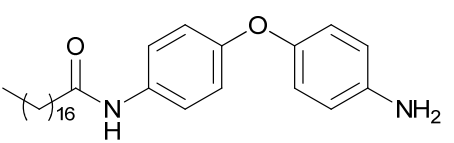

$70 \%, 12 \mathrm{~h}$
20 Scheme 31. Direct amidation of stearic acid using a nano sulfated titania catalyst (Hosseini-Sarvari, 2011).

The nano-sulfated titania catalyst was also demonstrated to be efficient in the formylation of amino substituted $\beta$-lactams at 25 room temperature. ${ }^{121}$ It was found that the previously developed $\mathrm{ZnO}$-catalysed $\mathrm{N}$-formylation protocol failed in the case of $\beta$ lactam substrates. ${ }^{116}$ However, the nano-sulfated $\mathrm{TiO}_{2}(0.015$ mol\%) displayed a high catalytic activity using equimolar amounts of the $\beta$-lactams and formic acid (Scheme 32).

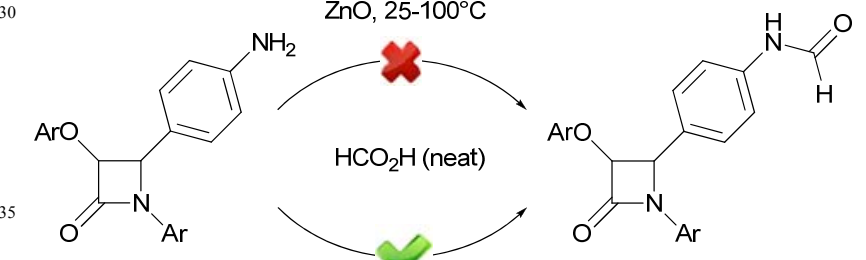

nano-sulfated $\mathrm{TiO}_{2}$ room temperature<smiles>CCOc1ccc(N2C(=O)C(Oc3ccccc3)C2c2ccc(NC=O)cc2)cc1</smiles>

$95 \%$

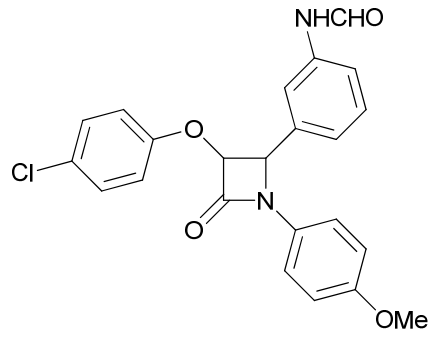

$75 \%$
${ }_{50}$ Scheme 32. $N$-formylation of $B$-lactams catalysed by nanosulfated titania (Hosseini-Sarvari, 2012).

The authors suggested that the difference in activity could be explained in terms of larger catalyst surface area and the amount 55 of sulfuric acid suspended on the titania. The catalyst showed excellent recyclability with a negligible decrease in yields after six cycles.
A similar sulfated titania catalyst was discovered by ${ }_{60}$ Swaminathan to be efficient in the $\mathrm{N}$-formylation at room temperature. ${ }^{122}$ Most $N$-formylation protocols with formic acid report on solvent-free procedures and that the addition of solvent reduces the efficiency of the catalysis. However, Swaminathan and co-workers found that excellent yields of formanilide could ${ }_{65}$ be obtained in the presence of acetonitrile, chloroform, dichloromethane and ethanol. The titania catalyst could be filtered off at the end of the reaction and re-used five times with negligible loss in activity.

70 Nagarajan et al. reported on the synthesis and catalytic activity of sulfated titania nanotubes. ${ }^{123}$ The nanotubes had a length of several hundred $\mathrm{nm}$ with diameters of around 3-6 nm, and the authors showed that if the nanotubes were prepared from calcination of the titania nanoparticles at 400,600 or $800{ }^{\circ} \mathrm{C}$, the 75 tubes would bundle together and therefore display a smaller surface area. The authors observed that the calcinated catalysts were less active in the amidation reaction, which was attributed to the larger particle size, and hence smaller surface area. In the amidation of phenylacetic acid with aniline, the product was 80 formed in $98 \%$ yield at $110{ }^{\circ} \mathrm{C}$ under solvent free conditions with a catalyst loading of $24 \mathrm{wt} \%$. The thermal yield was found to be $45 \%$ under the same reaction conditions. Moreover, a correlation between the catalyst activity and the sulfur content in the nanostructure was observed. Calcinated nanoparticles, which 85 were found to have a lower sulfur content, were less active as catalysts and the recyclability study revealed that sulfur was leaching, leading to a steady decrease of the catalytic activity in subsequent cycles.

90 An efficient and recyclable aluminium oxide catalyst was developed by Thakur and co-workers for the $N$-formylation of amines. ${ }^{124}$ With $5 \mathrm{~mol} \%$ of a nano rod-shaped basic $\mathrm{Al}_{2} \mathrm{O}_{3}$ catalyst, formanilide was obtained in $98 \%$ yield after only 5 min at $40{ }^{\circ} \mathrm{C}$ (TON $78 /$ TOF $945 \mathrm{~h}^{-1}$ ) from aniline and formic acid.

95 This should be compared to the thermal amidation which resulted in 28 and $42 \%$ yield at 40 and $70{ }^{\circ} \mathrm{C}$, respectively, after 7-10 h. A range of substrates including both electron-rich and electron-poor aromatic amines, unprotected amino acids (glycine and valine), phenylhydrazine, diamines, and $N$-heterocycles were formylated 100 in high to excellent yields (Scheme 33). The recycling of the catalyst proved to be successful and no decrease in product yield was observed after 5 cycles. 


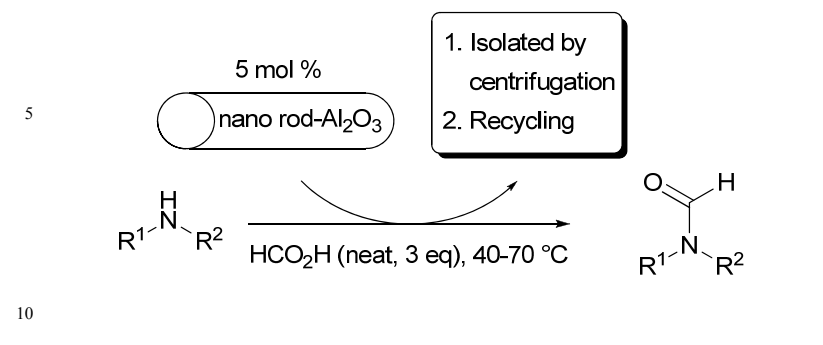

NCHO<smiles>O=CNc1ccccc1</smiles><smiles>O=Cn1ccnc1</smiles>

$>98 \%, 5 \mathrm{~min}$

$90 \%, 45 \mathrm{~min}$

$85 \%, 90 \mathrm{~min}$<smiles>CC(C)C(NC=O)C(=O)O</smiles><smiles>O=CN1CCN(C=O)CC1</smiles>

$98 \%, 30 \mathrm{~min}$<smiles>N#CCc1c[nH]c2ccccc12</smiles>

$90 \%, 30 \mathrm{~min}$

${ }_{25}$ Scheme 33. $N$-formylation of amines with a recyclable aluminium oxide catalyst (Thakur, 2012).

Alumina beads (3-5 $\mathrm{mm}$ in size) were demonstrated to be an easily available, clean and reusable heterogeneous catalyst for the 30 carboxylic acid/amine condensation. ${ }^{125}$ In contrast to the sulfated titania nanoparticles which were deactivated upon calcination, the alumina beads displayed a higher catalytic activity with increasing calcination temperatures. The highest activity was observed after calcination at $700{ }^{\circ} \mathrm{C}$ upon which the morphology

35 of the material changed from spherical to rhombohedral. The authors noted that even though the aggregation of the particles increased after calcination, hence decreasing the surface area, the pore volume and pore width increased. The authors suggested that the increase in pore volume gave a favourable diffusion of

40 the substrates and products, which could explain the observed higher activity. The activated alumina catalyst was compared to a non-activated catalyst in the reaction between heptanoic acid and p-chloroaniline at $140{ }^{\circ} \mathrm{C}$ without any solvent, using a $10 \mathrm{wt} \%$ catalyst loading. The non-activated catalyst led to $65 \%$ 45 conversion after 3 hours: considerably lower than the $98 \%$ which was obtained for the calcinated catalyst. Despite the high reaction temperature, no product formation was observed in the absence of catalyst. The catalytic protocol was effective for a variety of amines and carboxylic acids, and the catalyst could easily be

${ }_{50}$ filtered off and re-used up to three times with a minor decrease in activity (Figure 12).<smiles>COc1ccc(NC(=O)C2CC2)cc1</smiles><smiles>COc1ccc(NC(=O)c2ccc([N+](=O)[O-])cc2)cc1</smiles>

$80 \%$ $78 \%$<smiles>O=C(NCc1cccc2ccccc12)C1CC1</smiles><smiles>CCCC(=O)Nc1ccc2cc3ccccc3cc2c1</smiles>

$69 \%$<smiles>CCCCCCC(=O)NC(C)C</smiles><smiles>CCCCCCC(=O)N1CCCC1</smiles>

$95 \%$ $80 \%$

Figure 12. Selected examples for the catalytic amidation with a recyclable alumina catalyst (Mukhopadhyay, 2012).

Akamanchi and co-workers reported on an efficient process for the direct amidation of various carboxylic acids, employing sulfated tungstate as a heterogeneous acid catalyst. ${ }^{126}$ The catalyst was evaluated against other acid catalysts such as $p$ 85 toluenesulfonic acid, camphorsulfonic acid and silica in the formation of $N$-benzylbenzamide, and sulfated tungstate was found to be a superior catalyst (Scheme 34).<smiles>O=C(O)c1ccccc1</smiles>

$16.4 \mathrm{mmol}$

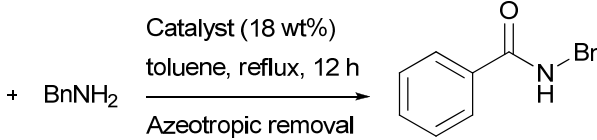
$14.9 \mathrm{mmol}$ of water

\section{Catalyst}

Sulfated tungstate $\mathrm{H}_{3} \mathrm{PW}_{12} \mathrm{O}_{40}$ p-toluenesulfonic acid 10<smiles>O=C(Nc1ccccc1)c1ccccc1</smiles>

$45 \%, 14 \mathrm{~h}$ 105<smiles>O=C(c1ccccc1)N1CCCCC1</smiles>

$33 \%, 24 \mathrm{~h}$
Yield (\%) Catalyst

Camphorsulfonic acid 12
100

110

Scheme 34. Catalytic performance of sulfated tungstate in comparison with other acid catalyst (Akamanchi, 2010).

The substrate scope included 12 examples of amides formed 115 within 12-24 h, and the thermal amidation reaction did not exceed $26 \%$ for any of the substrates. Furthermore, the catalytic 
performance of the sulfated tungstate material was evaluated in the $\mathrm{N}$-formylation of amines. ${ }^{127}$ It was demonstrated that $p$ chloroaniline was formylated in $98 \%$ yield at $55^{\circ} \mathrm{C}$ with $10 \mathrm{wt} \%$ of the catalyst and 2.5 hours reaction time. However, the reaction 5 was considerably faster at $70{ }^{\circ} \mathrm{C}$, and the $p$-chloro formanilide was obtained in the same yield after only 10 minutes, using a slight excess of the formic acid. A range of amines were efficiently formylated in short reaction times, and full chemoselectivity in favour of $N$-formylation was obtained when 10 hydroxy-substituted substrates were employed. Moreover, full retention of the stereochemistry of enantiopure starting compounds was observed with this protocol (Scheme 35).

$$
\begin{aligned}
& \text { Sormic acid (1.2 eq) } \\
& \begin{array}{l}
\text { r.t., } 6 \mathrm{~h}, 80 \% \\
55^{\circ} \mathrm{C}, 2.5 \mathrm{~h}, 98 \% \\
70^{\circ} \mathrm{C}, 10 \mathrm{~min}, 98 \%
\end{array}
\end{aligned}
$$

20<smiles>O=CNc1ccccc1O</smiles><smiles>CC(NC=O)c1ccccc1</smiles>

$99 \%, 10 \mathrm{~min}$<smiles>O=C(c1ccccc1)N(c1ccccc1)c1ccccc1</smiles>

$87 \%, 45 \mathrm{~min}$<smiles>O=CNc1nccs1</smiles>

$87 \%, 10 \mathrm{~min}$<smiles>CCCN(C=O)CCC</smiles>

$84 \%, 30 \mathrm{~min}$
$95 \%, 10 \min$

Scheme 35. $N$-formylation of amines with a sulfated tungstate 35 catalyst (Akamanchi, 2012).

Clays such as montmorillonite and chamosite have been used as catalysts for the direct amidation. In 2001, Choudary and Kantam performed a study of different metal ion-exchanged 40 montmorillonites, as catalysts for the direct acylation of amines with acetic acid. ${ }^{128} \mathrm{~A} \mathrm{Fe}^{3+}$ exchanged K-10-montmorillonite was found to be the most efficient catalyst in the model reaction of benzylamine with acetic acid under solvent free conditions at 116 ${ }^{\circ} \mathrm{C}$. The amide was obtained in $99 \%$ yield after 5 minutes using a 45 catalyst loading of $20 \mathrm{mg} / \mathrm{mmol}$ substrate. The non-catalysed reaction gave rise to less than $5 \%$ yield after the same reaction time. Montmorillonites doped with $\mathrm{Cu}^{2+}, \mathrm{Al}^{3+}, \mathrm{Zn}^{2+}$, as well as the non-doped version, also resulted in high yields ( $>98 \%)$, although they all required longer reaction times (20-40 minutes).

${ }_{50}$ The scope of the Fe(III)-montmorillonite catalysed $\mathrm{N}$-acetylation was found to be quite broad, furnishing the acetamides in yields of $72-99 \%$ after 5-360 minutes (Figure 13). No racemisation occurred when $(R)-(+)-\alpha$-methylbenzylamine was acylated, and a $98 \%$ yield of the optically pure amide was obtained in $45 \mathrm{~min}$.

${ }_{55}$ This can be compared to the thermal non-catalysed reaction, which gave rise to $52 \%$ yield after 6 hours. The catalyst could be recycled and reused five times for the formation of the enantiomerically pure acetamide without any loss of activity.

Furthermore, it was also demonstrated that propionic and butyric 60 acid could be used as acylating agents using the Fe(III)montmorillonite catalyst.<smiles>CC(=O)NCc1ccccc1</smiles>

$99 \%, 5 \mathrm{~min}$.<smiles>CC(=O)NCc1ccccc1</smiles>

$98 \%, 60 \mathrm{~min}$.<smiles>CC(=O)Nc1ccccc1</smiles>

$98 \%, 180 \mathrm{~min}$.<smiles>CC(=O)Nc1ccc(O)cc1</smiles>

$98 \%, 180 \mathrm{~min}$.<smiles>C#CCNC(C)=O</smiles>

$72 \%, 240 \mathrm{~min}$.<smiles>CC(=O)NCc1cccnc1</smiles>

$95 \%, 210 \mathrm{~min}$.<smiles>CC(=O)NC1CCCCC1</smiles>

$97 \%, 180 \mathrm{~min}$<smiles>CC(=O)NCC(C)(C)C</smiles>

$98 \%, 210 \mathrm{~min}$<smiles>COC(=O)[C@H](Cc1ccccc1)NC(C)=O</smiles>

$96 \%, 120 \mathrm{~min}$.

Figure 13. Selected substrates from Fe(III)-montmorillonite90 catalysed protocol of Choudary and Kantam (2001).

The catalytic activity of the $\mathrm{Fe}^{3+}-\mathrm{K}-10$-montmorillonite clay was further investigated by Srinivas and Das. ${ }^{129}$ While the previous amidation method was performed under solvent-free 95 conditions at $116-120{ }^{\circ} \mathrm{C}$ and mainly utilized acetic acid as acylating agent, the group of Das performed the reaction at lower reaction temperature in refluxing chloroform (b.p. $61^{\circ} \mathrm{C}$ ). It was shown that both aromatic and aliphatic carboxylic acids could be coupled with aliphatic and aromatic amines in yields of $78-97 \%$ 100 of the corresponding amides. Compared to the neat reaction, a higher catalyst loading $(100 \mathrm{mg} / 1 \mathrm{mmol})$ and longer reaction times (7-9 hours) had to be employed.

The most recent example of the $\mathrm{Fe}^{3+}-\mathrm{K}-10$-montmorillonite 105 catalyst for direct amidation of carboxylic acids was presented by the group of Handique. ${ }^{130}$ It was reported that different aromatic carboxylic acids (caffeic, ferulic and p-coumaric acid) could be condensed with diamines and triamines to form polyphenolic amides in yields of $47-79 \%$, after $4-5$ hours of reaction time. A 110 screening of the catalytic properties of different $\mathrm{M}^{\mathrm{n+}}$ montmorillonites came to the same conclusion as earlier reports, namely that the $\mathrm{Fe}^{3+}$ exchanged clay was the most active species (Scheme 36). 


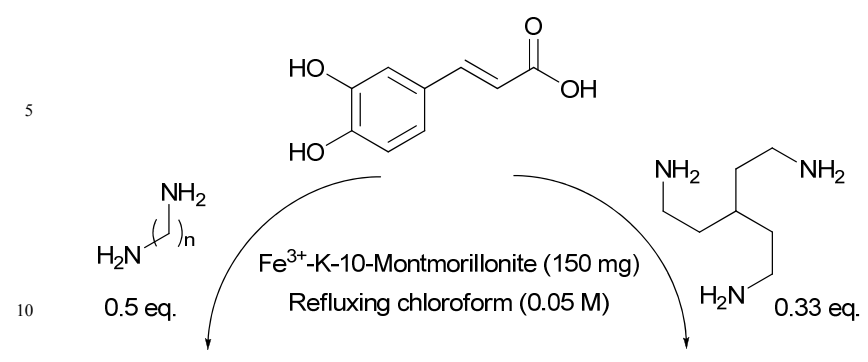

(25)<smiles>O=C(/C=C/c1ccc(O)c(O)c1)NCCC(CCNC(=O)/C=C/c1ccc(O)c(O)c1)CCNC(=O)/C=C/c1ccc(O)c(O)c1</smiles>

$$
\begin{aligned}
& n=2,73 \%, 4 h \\
& n=3,77 \%, 4 h \\
& n=4,76 \%, 4 h
\end{aligned}
$$

$68 \%, 5 \mathrm{~h}$

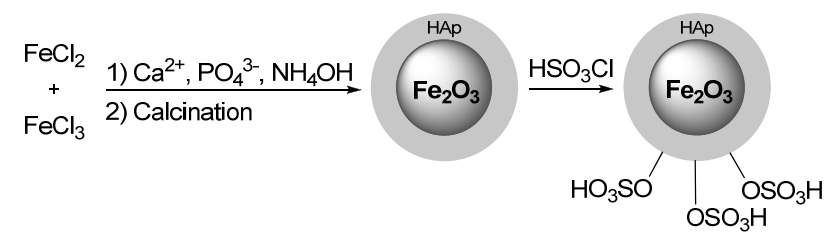

Scheme 37. Preparation of hydroxyapatite- $\gamma-\mathrm{Fe}_{2} \mathrm{O}_{3}$ supported sulfonic acid catalyst (Yamini, 2010).

Kumar et al. reported on an acylation protocol of alcohols and amines using a zirconium/yttrium-based heterogeneous catalyst. ${ }^{133}$ The Lewis acidic material was synthesised from yttrium nitrate and zirconyl nitrate and the chemical composition 75 of the solid material was determined to be $82.6 \mathrm{~mol} \%$ zirconium and $15.6 \mathrm{~mol} \%$ yttrium. Aniline and benzylamine were reacted with acetic acid and converted into the corresponding amides in $93 \%$ and $92 \%$ yield, respectively. 2-aminoethanol was turned into the corresponding acetamide in $94 \%$ yield with full 80 chemoselectivity in favour of $N$-acylation.

Elemental zinc was demonstrated to be an active $N$ formylation catalyst by the group of Jang. ${ }^{134}$ Various amines were reacted with formic acid ( $3 \mathrm{eq}$ ) for $0.5-12 \mathrm{~h}$ at $70{ }^{\circ} \mathrm{C}$ in the 85 presence of $10 \mathrm{~mol} \%$ activated zinc dust (pre-treated with $\mathrm{HCl}$ ). Primary and secondary amines, both aromatic and aliphatic, were successfully transformed into the corresponding formamides in yields of $71-96 \%$. The catalytic protocol was found to be selective for $N$ - vs. $O$-acylation, and neither phenol nor benzyl 90 alcohol were formylated even after $72 \mathrm{~h}$. The chemoselectivity was also illustrated by selective formylation of the amino group of 2-aminoethanol. The $N$-formylation of $\alpha$-amino acid esters was successfully performed without any racemisation of the stereocenter. A similar protocol has also been reported based on ${ }_{95}$ elemental indium as catalyst for the $N$-formylation. ${ }^{135}$

Recently, Xiao et al. found that a hafnium(IV) complex supported on fluorous silica gel was able to catalyse the $\mathrm{N}$ formylation of amines using aqueous formic acid. ${ }^{136}$ Hafnium(IV) 100 chloride was reacted with perfluorooctanesulfonylamide to form the water-tolerant Lewis acid complex which then was suspended onto the fluorous silica (Figure 14). Anilines, benzylamine and butylamine were transformed into the corresponding formamides in yields of $60-87 \%$ with the aid of $1 \mathrm{~mol} \%$ catalyst and reaction 105 times between $1-3 \mathrm{~h}$ at $70{ }^{\circ} \mathrm{C}$

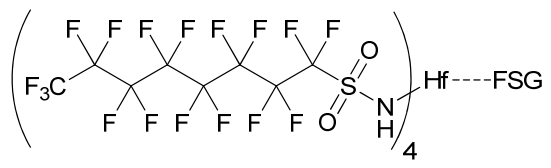

Figure 14. Water tolerant Hafnium(IV)-complex suspended on fluorous silica gel reported by Xiao et al. (2013).

115 Microwave irradiation was used by Talukdar et al. in the formation of $N$-methylamides from carboxylic acids and $N, N^{\prime}$ - 
dimethylurea with catalytic amounts of $\mathrm{ZrOCl} \bullet 8 \mathrm{H}_{2} \mathrm{O} .{ }^{137}$ Under solvent free conditions and $10 \mathrm{~mol} \%$ catalyst, a variety of amides were formed in $45-98 \%$ yield in short reaction times (Scheme 38). The catalyst could be reused up to four times without any 5 loss of activity, but no other ureas were demonstrated to work as amine source.

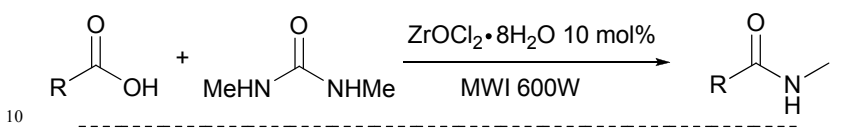

$$
\text { (20) }
$$<smiles>CNC(=O)c1ccc(O)cc1</smiles>

15<smiles>CNC(=O)/C=C/c1ccccc1</smiles><smiles>C=C(CC(=O)NC)C(=O)NC</smiles>

Scheme 38. Selected methylamides formed by Zr-catalysed amidation (Talukdar, 2011).

30 Coman et al. combined the features of ionic liquids and Lewis acids in a heterogeneous catalyst by immobilization onto a mesoporous MCM-41 support (Scheme 39). ${ }^{138}$ The material was used as a catalyst for direct amidation of acetic, propionic and butyric acid. In their synthesis of the solid support material, ionic 35 liquids (IL) based on butyl-substituted imidazolium salts were grafted onto the MCM-41 (IL-MCM), after which a metal-triflate (scandium triflate or zinc triflate) was anchored onto the material (ScIL-MCM and ZnIL-MCM).

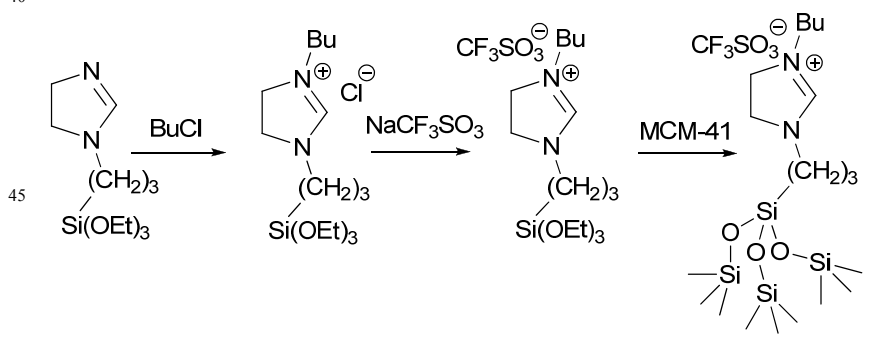

${ }_{50}$ Scheme 39. Immobilized ionic liquid for the preparation of ScIL-MCM and ZnIL-MCM (Coman, 2007).

In the reaction between aniline and acetic, propionic and butyric acid, it was found that the support without any Lewis acid (IL${ }_{55} \mathrm{MCM}$ ) was slightly more active as catalyst and no synergistic effects were found between the IL and the metal-triflates. The amidation was performed in a 1:10 ratio of the amine:acid at 80 ${ }^{\circ} \mathrm{C}$ for $21 \mathrm{~h}$. However, a strong synergistic effect between the ionic liquid and scandium-triflate could be seen when the reaction
60 was performed with aliphatic amines and acetic acid, as ScILMCM proved to be superior over the IL-MCM (Scheme 40).

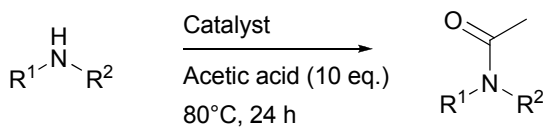

\begin{tabular}{llll} 
& & \multicolumn{2}{c}{ Conversion (\%) } \\
$\mathbf{R}^{\mathbf{1}}$ & $\mathbf{R}^{\mathbf{2}}$ & IL-MCM & ScIL-MCM \\
$n$-Butyl & $\mathrm{H}$ & 18.3 & 100 \\
$n$-Pentyl & $\mathrm{H}$ & 6.6 & 100 \\
$n$-Hexyl & $\mathrm{H}$ & 6.7 & 100 \\
Cyclohexyl & $\mathrm{Me}$ & 20.3 & 97.3
\end{tabular}

Scheme 40. The importance of scandium in the acylation of aliphatic amines (Coman, 2007).

In 2009, a catalytic system utilizing $\mathrm{FeCl}_{3}$ was reported for amide synthesis. The group of Kantam made use of nanofibers of polyaniline (PANI) as a support for iron(III) chloride (Figure $15) .{ }^{139}$

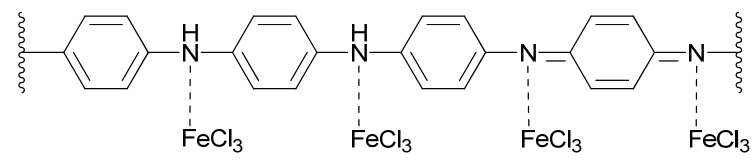

Figure 15. Iron doped nanofibers of polyaniline (Kantam, 2009).

The nanofiber material was employed as catalyst with a loading of $17 \mathrm{mg} / \mathrm{mmol}$ substrate in the acetylation of amines using acetic 90 acid in a 1:26 molar ratio at $100{ }^{\circ} \mathrm{C}$. A few substrates were efficiently transformed into the corresponding amides, including aniline (90\%), 4-fluoroaniline (96\%) and benzylamine (87\%), whereas other substrates, for instance cyclohexylamine (35\%), 2nitroaniline (36\%) and 2-methylaniline $(21 \%)$ were found to be 95 less reactive. The catalyst was also suitable for the acetylation of alcohols and could be recycled up to five times without loss of activity. No corresponding study of recyclability in the amidation reaction was however presented.

\section{5.3 Summary and conclusions on metal catalysis}

The literature on homogeneous metal catalysis for direct amidation of non-activated carboxylic acids is fairly limited, and it becomes clear that most of the catalytic complexes are based on early transition metals. Metal catalysis has a large potential in the 105 direct amidation due to the ease of tuning the metal centre by addition of ligands, and this area is at present underexplored. Generally, the metal catalysts that are presented in the literature require high to fairly high reaction temperatures in order to work, which can be a drawback for sensitive substrates. The majority of 110 the catalytic systems are inhibited by coordinating groups in the substrates. Removal of the formed water is also required in order to reach high conversions. However more successful than boronbased catalysis, very few methods for the formation of primary amines with homogeneous metal-catalysis are known. In this 115 respect, enzyme catalysis is superior despite the limited substrate scope of biocatalysts. 
The environmental benefits of catalytic direct amidation of carboxylic acids with amines can further be improved by the use of heterogeneous catalysts. The increasing number of catalytic protocols employing heterogeneous metal-containing materials 5 with good recyclability indicates that this pathway is indeed viable. However, these protocols are often limited to either $\mathrm{N}$ formylation or $N$-acetylation with formic or acetic acid, respectively. There are a few heterogeneous catalysts that have been reported to have a larger scope. For instance, the sulfated

10 tungstate catalyst developed by Akamanchi and co-workers and the nano-sulfated $\mathrm{TiO}_{2}$ catalyst prepared by the group of Hosseini-Sarvari, have proved to be efficient for both $\mathrm{N}$ formylation as well as for $\mathrm{N}$-acylation of other carboxylic acids. ${ }^{117,118,123,124}$ The fields of homogeneous and heterogeneous

15 metal-based catalysis for direct amidation remain underdeveloped areas and future improvements is likely to be seen.

\section{Miscellaneous catalysts}

Apart from enzymes, boric and boronic acids and metal-based catalysts, there are a handful of reports which report on direct 20 amide formation with other types of catalysts.

Shteinberg et al. studied various phosphorous-based catalysts in the amidation of benzoic acid with aniline. ${ }^{140}$ Several trivalent phosphorous compounds and one phosphorous(V) compound 25 were reported to show a catalytic activity. The reaction required elevated reaction temperatures in order to work, and was performed either in refluxing $o$-xylene $\left(\right.$ bp $145{ }^{\circ} \mathrm{C}$ ) or in decane (bp $174{ }^{\circ} \mathrm{C}$ ). Despite the high reaction temperatures, the uncatalysed thermal reaction was reported to be only $5 \%$ and $9 \%$,

30 respectively. With $2 \mathrm{~mol} \%$ of the catalyst, the best results were obtained with $\mathrm{PCl}_{3}, \mathrm{PBr}_{3}, \mathrm{H}_{3} \mathrm{PO}_{3}$ and $(\mathrm{EtO})_{2} \mathrm{P}(\mathrm{O}) \mathrm{H}$ in refluxing decane with 7 hours of reaction time (Scheme 41). Since not only phosphorous halides were reported to display a catalytic activity, it was suggested that a benzoyl halide is not an intermediate in 35 the reaction mechanism. Rather, the formation of benzanilide was proposed to take place via a reactive acyl phosphite intermediate.
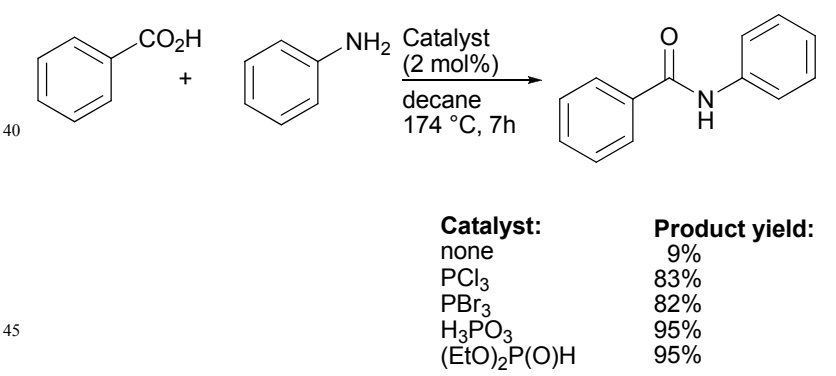

Scheme 41. Phosphorous-catalysed formation of benzanilide (Shteinberg, 1992).

50 The use of quaternary nitrogen compounds as catalysts in the amidation reaction was first demonstrated by Kunishima et al. With $10 \mathrm{~mol} \%$ of 1,3,5-triazine reagents (Figure 16) in a micellar phase, fatty acid sodium salts were coupled with n-butylamine in an aqueous solution. ${ }^{141}$ In the reaction between the fatty acid and

55 the catalyst, a marked rate enhancement was observed when the carbon chain of both substrate and catalyst were long enough to efficiently form a micellar aggregate. Moreover, it was shown that the reaction could take place in micelles formed by common surfactants. ${ }^{142}$ At room temperature using $30 \mathrm{~mol} \%$ catalyst in a ${ }_{60}$ phosphate buffer ( $\mathrm{pH} 8$ ), the amide of n-butylamine and sodium octanoate was obtained in $8 \%$ yield without a surfactant present. However, the yield was increased to $50 \%$ when sodium 1decanesulfonate (DSA) was used in a concentration of five times the critical micelle concentration.$$
65
$$

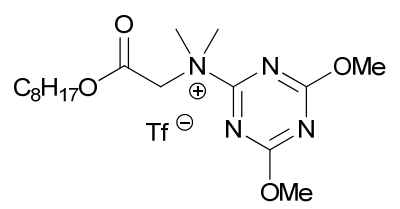

Figure 16. Condensing agent used in catalytic amounts under micellar conditions for amide formation of fatty acid sodium salts with n-butylamine (Kunishima, 2012).

A similar catalyst was studied by Lei et al. for the formylation of amines with formic acid. ${ }^{143}$ The catalytic activity of a thiamine hydrochloride salt ( $2 \mathrm{~mol} \%$ ) was demonstrated with 18 examples to obtain the corresponding formamides in $87-96 \%$ yield at $80{ }^{\circ} \mathrm{C}$ 80 (Figure 17). No thermal amidation was observed with aniline, even at $100{ }^{\circ} \mathrm{C}$ in the absence of the thiamine catalyst. The reaction was found to be selective for $N$ - versus $O$-acylation, and the scope of the acylating agent could be extended to include acetic, propionic and butyric acid for the acylation of aniline ${ }_{85}$ However, cinnamic and benzoic acid, as well as amines containing a carboxylic acid functionality, were not suitable as substrates for the reaction. The latter was explained to most likely be due to an intramolecular salt formation, which reduces the amine nucleophilicity.

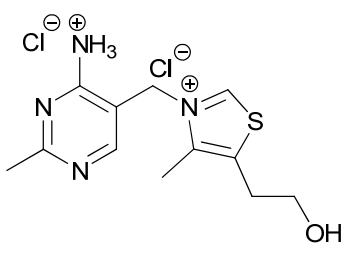

Figure 17. Thiamine catalyst developed by Lei et al. (2010).

100

Brahmachari et al. showed that sodium formate was an efficient catalyst for the formylation of a range of different amines under solvent free conditions at room temperature. ${ }^{144}$ By employing $20 \mathrm{~mol} \%$ of sodium formate and a four-fold molar 105 excess of formic acid, 27 examples of formamides (80-99\% yield) were reported. The sodium formate could be recovered and reused four times in the formylation of 4-bromoaniline without any loss of activity. The authors also reported that the reaction conditions were selective for $\mathrm{N}$-acylation with respect to $\mathrm{O}$ 110 acylation for both aromatic and aliphatic substrates. Majumdar et al. recently reported that different imidazolium-based protic ionic liquids were active catalysts for the same transformation. ${ }^{145}$ The formylation of several nitrogen- and oxygen-based nucleophiles was effective with $5 \mathrm{~mol} \%$ catalyst under solvent-free conditions 15 at $70{ }^{\circ} \mathrm{C}$. The optimal ratio of formic acid to amine was found to 
be 1.4:1, and acetic acid could as well be used as acylating agent under similar conditions. Another method for the $N$-formylation of amines was reported by Kim and Jang, employing $5 \mathrm{~mol} \%$ of molecular iodine as catalyst. ${ }^{146}$ High to excellent yields (69-96\%) 5 of the corresponding formamides were obtained from anilines, and primary and secondary amines using two equivalents of formic acid. The reaction performed optimally under solvent free conditions at $70{ }^{\circ} \mathrm{C}$, and with reaction times of 2-8 hours.

10 The use of metal-free mesoporous materials as recyclable catalysts has recently gained some interest. Luque and coworkers found that a sulfonated mesoporous material, derived from acidic polysaccharides (Starbon ${ }^{\circledR}-400-\mathrm{SO}_{3} \mathrm{H}$ ), was efficient as amidation catalysts under microwave irradiation. ${ }^{147} \mathrm{~A}$ catalyst

15 loading of $50 \mathrm{mg}$ per $1 \mathrm{mmol}$ amine was used in the acetylation of amines with acetic acid at a maximum temperature of $130{ }^{\circ} \mathrm{C}$. The corresponding acetamides were obtained in $68-99 \%$ yields in short reaction times $(<15$ minutes $)$. Additionally, six other carboxylic acids were also employed in the reaction with 20 benzylamine (Figure 18). The solid catalyst could be recovered and reused at least three times without any loss of activity<smiles>CC(=O)Nc1ccccc1</smiles>

25 $87 \%, 10 \mathrm{~min}$<smiles>CC(=O)Nc1ccc([N+](=O)[O-])cc1</smiles>

$92 \%, 2 \mathrm{~min}$<smiles>CC(=O)Nc1ccc(O)cc1</smiles>

$89 \%, 3 \mathrm{~min}$<smiles>CC(=O)NCc1cccnc1</smiles>

$79 \%, 5 \min$<smiles>CC(=O)N(C)Cc1ccccc1</smiles>

$94 \%, 3 \mathrm{~min}$<smiles>CC(=O)NC1CCCCC1</smiles>

$92 \%, 1 \mathrm{~min}$

35<smiles>O=C(CCCc1ccccc1)NCc1ccccc1</smiles>

$92 \%, 10 \min$<smiles>CCC(Cc1ccccc1)C(=O)NCc1ccccc1</smiles>

$84 \%, 10 \mathrm{~min}$

40 Figure 18. Selection of the substrate evaluation in the protocol by Luque and Clark (2009).

A catalytic protocol based on activated amorphous K60 silica was developed by Comerford et al. ${ }^{148}$ In refluxing toluene, 12 45 different amides were synthesized in isolated yields of $20-81 \%$, using $20 \mathrm{~mol} \%$ catalyst. Higher yields were often observed with an increased catalyst loading, and the thermal reaction was generally low (0-10\%). A notable exception was the amidation of propionic acid with butylamine which gave rise to $89 \%$ product 50 yield after 24 hours without any catalyst present. The system proved to be tolerant towards water formed in the reaction, and reactivation of the solid catalyst at $700{ }^{\circ} \mathrm{C}$ made it possible to recycle the material at least five times without loss of activity. An improved silica catalyst (SBA-15) with a well-defined 55 mesoporous structure was shown to be more catalytically active than the K60 silica. ${ }^{149}$ Similar yields were obtained with the SBA-15 catalyst, however a lower catalyst loading ( $5 \mathrm{~mol} \%$ vs. $20 \mathrm{~mol} \%$ ) could be utilized (Scheme 42). In addition, when the

mesoporous SBA-15 catalyst and the amorphous K60 silica were 60 used in a flow reactor, the SBA-15 silica displayed a higher activity based on weight.

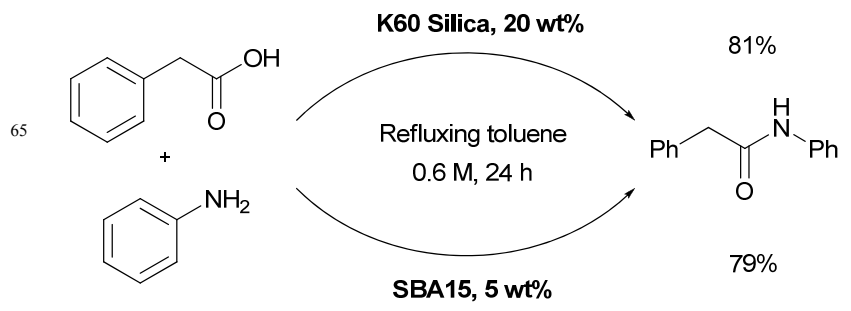

$70 \quad 12 \mathrm{mmol} / \mathrm{1:1}$ ratio

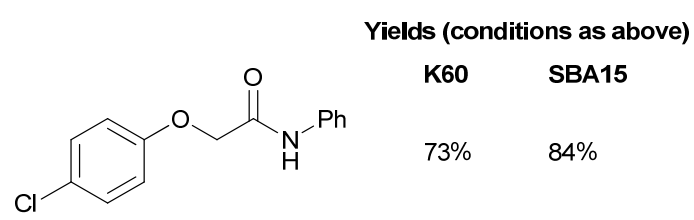
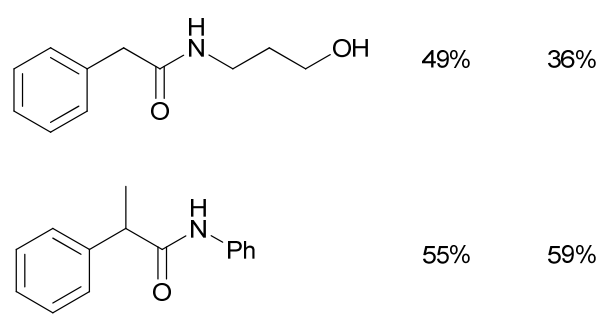

Scheme 42. K60 Silica and SBA-15 catalysis by Comerford et al. (2009 and 2012).

90 Another mesoporous silica, MCM-41, was shown by Komura et al. to be an efficient catalyst for the amidation of fatty acids and long-chain aliphatic amines. ${ }^{150}$ In the coupling of palmitic acid and n-hexylamine in refluxing toluene, $20 \mathrm{~mol} \%$ of the MCM-41 catalyst furnished the product in 94\% yield after 6 ${ }_{95}$ hours using a Dean-Stark apparatus. Seventeen additional examples of amide products were presented with yields of 85 $>99 \%$ for primary unhindered amines, whereas more sterically hindered amines (tert-butylamide, $\mathrm{N}, \mathrm{N}$-dihexylamine and cyclohexylamine) gave rise to considerably lower yields with 100 palmitic acid (0, 3 and 59\%, respectively). Filtration and calcination of the catalyst, allowed for recycling in 3 additional cycles.

Malakooti et al. published a protocol for the formylation of 105 amines using $20 \mathrm{~mol} \%$ of an aminopropylated SBA-15 (APMS) catalyst under solvent-free conditions. ${ }^{151} \mathrm{~A}$ range of aromatic and aliphatic amines, including diamines, cyclic amines, imidazole, aminoalcohols and the amino acid isoleucine were converted into the corresponding amides at $40-70{ }^{\circ} \mathrm{C}$ using a 2-10 molar excess 110 of the amine. Furthermore, full chemoselectivity in favor of $\mathrm{N}$ acylation was reported for substrates containing both hydroxyl and amine groups. The catalyst could be filtered off and recycled at least five times without loss of activity in the formylation of aniline.

There are some recent examples in the literature of $\mathrm{N}$ - 
formylation of amines catalysed by supported Brønstedt acids. Bhojegowd et al. reported on the heterogeneous acid Amberlite IR-120 as a formylation catalyst under microwave irradiation. ${ }^{152}$ A catalyst loading of $50 \mathrm{mg}$ per $1 \mathrm{mmol}$ substrate was employed 5 for the formylation of 17 anilines and 2 aliphatic amines with a three-fold excess of the formic acid. The formamides were obtained in $90-97 \%$ yield after 1-2 minutes when the mixture was irradiated at $320 \mathrm{~W}$ with 20 second intervals. Substrates containing free hydroxyl-groups were reported to display a full

10 chemoselectivity in favour of $N$-formylation, and the catalyst could be recycled at least five times with a difference in yield of $5 \%$ between the first and the fifth run. In addition, Ansari et al. screened the catalytic activity of various acid-functionalized silica species in the direct $\mathrm{N}$-formylation reaction of amines. ${ }^{153}$ Among 15 the screened species $\left(\mathrm{HClO}_{4}-\mathrm{SiO}_{2}, \mathrm{H}_{2} \mathrm{SO}_{4}-\mathrm{SiO}_{2}, \mathrm{HBF}_{4}-\mathrm{SiO}_{2}\right.$ and TFA-SiO ${ }_{2}$ ), the supported perchloric acid was the most catalytically active species. The amidation could be performed at ambient temperature employing $2.5 \mathrm{~mol} \%$ of $\mathrm{HClO}_{4}-\mathrm{SiO}_{2}$ giving rise to yields in the range of $70-96 \%$. The catalyst could be

20 filtered off after the reaction and reused three times. However, a significant drop in product yield was observed in the third cycle.

\section{Conclusions/discussion}

Alternatives to the traditional approaches to amide formation, which employs coupling reagents with low cost- and waste25 efficiency, are starting to find their way into the tool-box of the organic chemist. Although catalysis for direct amidation is still in its infancy, the emerging methodologies for the transformation mirror the need for new environmentally conscious chemistry. To date, the number of published catalytic protocols is still limited.

${ }_{30}$ As can be seen in this review, there are two main types of catalysts that have been used: enzymes and Lewis acids, where the latter type can be divided into two sub-groups of boron-based and metal-based catalysts. In addition, there is a handful of other catalyst types.

35

The advantage of Lewis acid-based catalysts over biocatalysts is generally that the substrate scope is considerably wider, the reaction times are shorter and the catalysts are usually easier to access. However, most of these catalysts need elevated reaction 40 temperatures which limit their applicability, although there are a few exceptions. In addition, water removal is often needed in order for the catalysts to work efficiently. Metal-based homogeneous catalysts are also often sensitive towards coordinating groups in the substrates, which can lead to inhibition 45 of the catalytic cycle. To address these problems, the use of different ligands in order to tune the central atom of the Lewis acid catalysts is promising. This possibility makes these catalyst types interesting for future development of selective protocols functioning under mild conditions.

The main advantage of enzymatic protocols is that they are usually milder than Lewis acid-based methods and work at lower temperatures. As long as the starting materials to the target amide is compatible with the biocatalyst, enzymatic protocols might 55 well be the best choice for sensitive substrates to date. The substrate scope of the biocatalyst, which is often limited, can be expanded by changing the structure of the enzyme by directed evolution.

60 The field of heterogeneous metal-based catalysis is rapidly growing, especially in the field of metal nanoparticle catalysts. Recent improvements in their preparation and characterization make it possible to modify the size and shape of the nanoparticles on a molecular level, which has been shown to have a strong ${ }_{65}$ influence of efficiency and selectivity in catalytic reactions. ${ }^{154}$ However, the protocols using heterogeneous metal-based catalysts for direct amidation are mainly focused on $\mathrm{N}$ formylation or $\mathrm{N}$-acetylation of amines, with a few exceptions. Solid-supported boronic acids usually display a wider substrate 70 scope while offering high stability and efficient recyclability. The reported protocols for direct amidation with biocatalysis have most often employed immobilized enzymes as catalyst, due to their high stability and easy handling, however they also suffer from a low substrate scope. In general, hetereogeneous catalysed 75 direct amidation of carboxylic acids remain an underdeveloped topic. A stable, efficient and selective recyclable catalyst would be a valuable contribution to green catalysis in this field of chemistry.

80 It is likely that catalytic protocols for direct amidation will have its first and perhaps largest impact on small molecules containg the amide functionality. However, future extension of the methods to include the formation of peptides would be highly valuable. To date, the enzyme-catalysed solid-supported protocol 85 by Ulijn et al. is the only example of catalytic protocols for the formation of protected dipeptides. ${ }^{31}$ In addition, the stoichiometric boronic acid-mediated protocol by Whiting and co-workers is suggesting that this catalyst type might be a promising future alternative. ${ }^{71}$ An advantage of using a non90 biological catalyst could be the possibility of introducing unnatural amino acids which a biocatalyst would exclude. A catalytic protocol combining such a strategy with the kinetic resolution of a racemic amino acid, could very well serve as a valuable new route to novel chiral peptides with a well-defined 95 stereochemistry. There is to date one example of a boronic acidbased chiral catalyst for kinetic resolution of amines, however resulting in considerably lower $e e$ 's in the amide product compared to enzyme-mediated protocols. ${ }^{77}$ No chiral metal-based catalysts are yet known for this transformation. The strategy of 100 adding a chiral ligand to a metal center to render an enantioselective version of a racemic catalytic reaction is however well-established in the field of metal catalysis, and it is not unlikely that such a strategy will prove viable in the field of direct amidation as well. Further development of ligands to Lewis 105 acid catalysts could also help to solve the problems with reactivity, which coordinating functional groups in the substrate or product often give rise to. The possibility of using starting materials without hydrophobic protecting groups in catalytic direct amidation would indeed be valuable for future application 10 in peptide synthesis.

Despite the wide range of applications for polyamide materials, there is only one catalytic example for direct amidation of a linear polyamide, developed by Yamamoto and co-workers. ${ }^{62}$ 115 Even though this protocol is the only successful catalytic method 
for the formation of polyamides via direct amidation, it also suffers from problems such as a high polydispersity in the product. In a review from 2011, Bode notes that commercially produced polyamides usually lack unprotected functionalities and 5 complex stereochemistry, which could give rise to unique and powerful properties. ${ }^{9 \mathrm{e}}$ To incorporate such elements in a controlled way into the polymers remains a considerable synthetic challenge. Clever catalysis might very well be the tool needed in order to enable the formation of new functional 10 materials with novel properties.

Today, a number of green catalytic protocols for amide bond formation between carboxylic acids and amines have been developed. However, there are still several problems that need to 15 be solved before catalysis can compete with the waste-intensive but efficient use of coupling reagents. Before catalysis can become a real alternative for large-scale production of e.g. pharmaceuticals, peptides and polyamide materials, further advancements in the field is needed. Below, some of the 20 remaining challenges for direct amidation catalysts are listed:

- High yielding at low temperatures and high concentrations

- High functional group tolerance and large substrate scope: allowing sterical hindrance and coordinating groups in the substrates

- Mild reaction conditions, allowing for a minimal epimerization of stereocenters

- High chemoselectivity for $\mathrm{N}$-acylation over e.g. $\mathrm{O}$ - or $S$-acylation

- Efficient without removal of the formed water

Detailed mechanistic understanding of known catalytic direct amidation reactions will likely be important in order to address 35 these challenges. Catalytic protocols which allow for the efficient synthesis of oligo- and polypeptides as well as novel polyamide materials would indeed become very valuable. The generation of water as the only byproduct makes the amide bond formation an ideal reaction in the environmentally and financially conscious 40 future in both academia and industry. The opportunities these challenges represent should serve as an inspiration for today's chemists to develop the chemistry of tomorrow.

\section{Acknowledgements}

${ }_{45}$ We are grateful for financial support from the Swedish Research Council and the K \& A Wallenberg foundation.

\section{Notes and references}

${ }^{a}$ Stockholm University, Department of Organic Chemistry, Arrhenius Laboratory, 106 91, Stockholm, Sweden Fax: +46 8 154908; Eso mail:hans.adolfsson@su.se (HA) nicklas@organ.su.se (NS)

1 A. K. Ghose, V. N. Viswanadhan and J. J. Wendoloski, J. Comb. Chem., 1999, 1, 55-68.

2 J. S. Carey, D. Laffan, C. Thomson and M. T. Williams, Org. Biomol. Chem., 2006, 4, 2337-2347.
3 S. D. Roughley and A. M. Jordan, J. Med. Chem., 2011, 54, 34513479.

4 T. J. Deming, Prog. Polym. Sci. 2007, 32, 858-875.

5 M. B. Smith and J. March, March's Advanced Organic Chemistry: Reactions, Mechanisms, and Structure, 5th Edition, John Wiley \& Sons, Ltd., 2000, pp. 508-510.

6 C. Montalbetti and V. Falque, Tetrahedron, 2005, 61, 10827-10852.

7 (a) S. Y. Han and Y. A. Kim, Tetrahedron, 2004, 60, 2447-2467. (b) E. Valeur and M. Bradley, Chem. Soc. Rev., 2009, 38, 606-631. (c) A. El-Faham and F. Albericio, Chem. Rev., 2011, 111, 6557-6602

8 D. J. C. Constable, P. J. Dunn, J. D. Hayler, G. R. Humphrey, J. L. Leazer, R. J. Linderman, K. Lorenz, J. Manley, B. A. Pearlman, A. Wells, A. Zaks and T. Y. Zhang, Green Chem., 2007, 9, 411-420.

9 (a) C. L. Allen and J. M. J. Williams, Chem. Soc. Rev., 2011, 40, 3405-3415. (b) S. Roy, S. Roy and G. W. Gribble, Tetrahedron, 2012, 68, 9867-9923.

10 (a) V. Gotor, Bioorg. Med. Chem., 1999, 7, 2189-2197. (b) F. van Rantwijk, M. Hacking and R. A. Sheldon, Mon. Chem., 2000, 131, 549-569. (c) K. Ishihara and H. Yamamoto, Eur. J. Org. Chem., 1999, 527-538. (d) K. Ishihara, Tetrahedron, 2009, 65, 1085-1109. (e) V. R. Pattabiraman, J. Bode, Nature, 2011, 480, 471-479. (f) E. Dimitrijević and M. S. Taylor, ACS Catal., 2013, 3, 945-962. (g) R. M. Lanigan and T. D. Sheppard, Eur. J. Org. Chem., 2013, 74537465. (h) B. M. Monks and A. Whiting, in Sustainable Catalysis: Challenges and Practices for the Pharmaceutical and Fine Chemical Industries, $1^{\text {st }}$ Ed., John Wiley \& Sons, Inc., 2013, pp. 89-110.

11 H. Charville, D. Jackson, G. Hodges and A. Whiting, Chem. Commun., 2010, 46, 1813-1823.

12 C. Grosjean, J. Parker, C. Thirsk and A. R. Wright, Org. Process Res. Dev., 2012, 16, 781-787.

13 C. L. Allen, A. R. Chhatwal and J. M. J. Williams, Chem. Commun., 2012, 48, 666-668.

14 M. Rahman, D. Kundu, A. Hajra, A. Majee, Tetrahedron Lett. 2010, 51, 2896-2899

15 H. Lundberg, F. Tinnis and H. Adolfsson, Chem. Eur. J., 2012, 18, 3822-3826.

16 V. Čeřovský and M.-R. Kula, Angew. Chem. Int. Ed., 1998, 37, 18851887.

17 V. Čeřovský and M.-R. Kula, Biotechnol. Appl. Biochem., 2001, 33, 183-187.

18 T. Nuijens, E. Piva, J. A. W. Kruijtzer, D. T. S. Rijkers, R. M. J. Liskamp and P. Quaedflieg, Tetrahedron Lett., 2012, 53, 3777-3779.

19 M. J. J. Litjens, A. J. J. Straathof, J. A. Jongejan and J. J. Heijnen, Chem. Commun., 1999, 1255-1256.

20 M. J. J. Litjens, A. J. J. Straathof, J. A. Jongejan and J. J. Heijnen, Tetrahedron, 1999, 55, 12411-12418.

21 W. F. Slotema, G. Sandoval, D. Guieysse, A. J. J. Straathof and A. Marty, Biotechnol. Bioeng., 2003, 82, 664-669.

22 W. E. Levinson, T. M. Kuo and D. Weisleder, J. Am. Oil Chem. Soc., 2005, 82, 501-504.

23 T. M. Kuo and W. E. Levinson, J. Am. Oil Chem. Soc., 2006, 83, 671-675.

24 W. E. Levinson, T. M. Kuo and G. Knothe, Bioresour. Technol., 2008, 99, 2706-2709.

25 R. M. Lau, F. van Rantwijk, K. R. Seddon and R. A. Sheldon, Org. Lett., 2000, 2, 4189-4191.

26 R. Maruyama, S. Ono and M. Inoue, Tetrahedron Lett., 2000, 41, 5229-5232.

27 R. Maruyama, A. Kawata, S. Ono, M. Nishizawa, S. Ito and M. Inoue, Biosci. Biotechnol. Biochem., 2001, 65, 1761-1765.

28 M. Brunati, F. Marinelli, C. Bertolini, R. Gandolfi, D. Daffonchio and F. Molinari, Enzyme Microb. Technol., 2004, 34, 3-9.

29 H. F. Olivo, A. Osorio-Lozada and T. L. Peeples, Tetrahedron: Asymmetry, 2005, 16, 3507-3511.

30 B. Tuccio, E. Ferre and L. Comeau, Tetrahedron Lett., 1991, 32, $2763-2764$

31 R. V. Ulijn, B. Baragaña, P. J. Halling and S. L. Flitsch, J. Am. Chem. Soc., 2002, 124, 10988-10989.

32 T. Maugard, M. Remaud-Simeon, D. Petre and P. Monsan, Tetrahedron, 1997, 53, 5185-5194. 
33 T. Maugard, M. Remaud-Simeon and P. Monsan, Biochim. Biophys. Acta: Protein Struct. Molec. Enzym., 1998, 1387, 177-183.

34 T. Maugard, M. Remaud-Simeon, D. Petre and P. Monsan, Tetrahedron, 1997, 53, 7587-7594.

35 F. Le Joubioux, O. Achour, N. Bridiau, M. Graber and T. Maugard, J. Mol. Catal. B: Enzym., 2011, 70, 108-113.

36 F. Le Joubioux, Y. Ben Henda, N. Bridiau, O. Achour, M. Graber and T. Maugard, J. Mol. Catal. B: Enzym., 2013, 85-86, 193-199.

37 M. Fernandez-Perez and C. Otero, Enzyme Microb. Technol., 2001, 28, 527-536.

38 M. Fernandez-Perez and C. Otero, Enzyme Microb. Technol., 2003, 33, 650-660

39 P. Tufvesson, A. Annerling, R. Hatti-Kaul and D. Adlercreutz, Biotechnol. Bioeng., 2007, 97, 447-453.

40 P. Plastina, J. Meijerink, J. P. Vincken, H. Gruppen, R. Witkamp and B. Gabriele, Lett. Org. Chem., 2009, 6, 444-447.

41 X. S. Wang, X. G. Wang and T. Wang, J. Agric. Food Chem., 2012, 60, $451-457$

42 M. Kidwai, R. Poddar and P. Mothsra, Beilstein J. Org. Chem., 2009, 5, No. 10.

43 M. Kidwai, R. Poddar and S. Bhardwaj, Biocatal. Biotransform., 2011, 29, 113-118

44 S. K. Khare, A. Kumar and T. M. Kuo, Bioresour. Technol., 2009, 100, 1482-1485.

45 A. Bose, N. A. Shakil, Pankaj, J. Kumar and M. K. Singh, J. Environ Sci. Health Part B: Pestic. Contam. Agric. Wastes, 2010, 45, 254261.

46 F. Lipmann and L. C. Tuttle, Biochim. Biophys. Acta, 1950, 4, 301309.

47 F. Servat, D. Montet, M. Pina, P. Galzy, A. Arnaud, H. Ledon, L. Marcou and J. Graille, J. Am. Oil Chem. Soc., 1990, 67, 646-649.

48 M. Hacking, H. Akkus, F. van Rantwijk and R. A. Sheldon, Biotechnol. Bioeng., 2000, 68, 84-91.

49 M. Hacking, F. van Rantwijk and R. A. Sheldon, J. Mol. Catal. B: Enzym., 2001, 11, 315-321.

50 R. Irimescu and K. Kato, Tetrahedron Lett., 2004, 45, 523-525.

51 R. Irimescu and K. Kato, J. Mol. Catal. B: Enzym., 2004, 30, 189194.

52 A. K. Prasad, M. Husain, B. K. Singh, R. K. Gupta, V. K Manchanda, C. E. Olsen and V. S. Parmar, Tetrahedron Lett., 2005, 46, 4511-4514.

53 M. Nechab, N. Azzi, N. Vanthuyne, M. Bertrand, S. Gastaldi and G. Gil, J. Org. Chem., 2007, 72, 6918-6923.

54 S. Gastaldi, S. Escoubet, N. Vanthuyne, G. Gil and M. P. Bertrand, Org. Lett., 2007, 9, 837-839.

55 M. T. Reetz, in Enzyme Catalysis in Organic Synthesis, Wiley-VCH Verlag GmbH \& Co. KGaA, 2012, pp. 119-190.

56 P. Nelson and A. Pelter, J. Chem. Soc., 1965, 5142-5144.

57 L. Y. Shteinberg, Russ. J. Org. Chem., 2003, 39, 972-974.

58 L. Y. Shteinberg, Russ. J. Appl. Chem., 2005, 78, 1715-1717.

59 L. Y. Shteinberg, Russ. J. Appl. Chem., 2006, 79, 1282-1285.

60 See the following articles for mechanistic studies of the system: (a) L. Y. Shteinberg, Russ. J. Appl. Chem., 2009, 82, 613-617. (b) L. Y. Shteinberg, Russ. J. Appl. Chem., 2011, 84, $815-819$

61 K. Ishihara, S. Ohara and H. Yamamoto, J. Org. Chem., 1996, 61, 4196-4197.

62 K. Ishihara, S. Ohara and H. Yamamoto, Macromolecules, 2000, 33, 3511-3513.

63 R. H. Tale and K. M. Patil, Tetrahedron Lett., 2002, 43, 9715-9716.

64 T. Maki, K. Ishihara and H. Yamamoto, Org. Lett., 2006, 8, 14311434.

65 R. Yamashita, A. Sakakura and K. Ishihara, Org. Lett., 2013, 15, 3654-3657.

66 P. Tang, in Advances in Controlled Drug Delivery: Science, Technology, and Products, eds. S. M. Dinh and P. Liu, American Chemical Society, Washington, 2003, vol. 846, pp. 103-111.

67 P. Tang, Org. Synth., 2005, 81, 262-272.

68 R. K. Mylavarapu, G. C. M. Kondaiah, N. Kolla, R. Veeramalla, P. Koilkonda, A. Bhattacharya and R. Bandichhor, Org. Process Res. Dev., 2007, 11, 1065-1068.
69 J. G. H. Barajas, L. Y. V. Mendez, V. V. Kouznetsov and E. E. Stashenko, Synthesis, 2008, 377-382.

70 K. Arnold, B. Davies, R. L. Giles, C. Grosjean, G. E. Smith and A. Whiting, Adv. Synth. Catal., 2006, 348, 813-820.

71 K. Arnold, A. S. Batsanov, B. Davies and A. Whiting, Green Chem., 2008, 10, 124-134.

72 S. Liu, Y. Yang, X. Liu, F. K. Ferdousi, A. S. Batsanov and A. Whiting, Eur. J. Org. Chem., 2013, 5692-5700.

73 R. M. Al-Zoubi, O. Marion and D. G. Hall, Angew. Chem. Int. Ed., 2008, 47, 2876-2879.

74 T. Marcelli, Angew. Chem. Int. Ed., 2010, 49, 6840-6843.

75 C. Wang, H.-Z. Yu, Y. Fu and Q.-X. Guo, Org. Biomol. Chem., 2013, 11, 2140-2146.

76 N. Gernigon, R. M. Al-Zoubi and D. G. Hall, J. Org. Chem., 2012, 77, 8386-8400.

77 K. Arnold, B. Davies, D. Herault and A. Whiting, Angew. Chem. Int. Ed., 2008, 47, 2673-2676.

78 K. Ishihara, S. Kondo and H. Yamamoto, Synlett, 2001, 1371-1374.

79 K. Ishihara, H. Yamamoto, Jpn. Kokai Tokkyo Koho JP 2001270939 (2001-10-02), Application: JP 2000-87495 (2000-03-27).

80 R. Latta, G. Springsteen and B. H. Wang, Synthesis, 2001, 16111613.

81 T. Maki, K. Ishihara and H. Yamamoto, Org. Lett., 2005, 7, 5043 5046.

82 T. Maki, K. Ishihara and H. Yamamoto, Tetrahedron, 2007, 63 , 8645-8657.

83 F. Tinnis, H. Lundberg and H. Adolfsson, Adv. Synth. Catal., 2012, 354, 2531-2536.

84 J. D. Wilson and H. Weingarten, Can. J. Chem., 1970, 48, 983-986

85 Werdehausen, A. And Weiss, H. Ger. Offen. DE2110060: Chem. Abstr. 1972, 77, 151518r.

86 Hull, E. H. Ger. Offen. DE2900231; Chem. Abstr. 1979, 91, 140591x.

87 K. Steliou and M. A. Poupart, J. Am. Chem. Soc., 1983, 105, 71307138 .

88 K. Steliou, A. Szczygielska-Nowosielska, A. Favre, M. A. Poupart and S. Hanessian, J. Am. Chem. Soc., 1980, 102, 7578-7579.

89 M. Mader and P. Helquist, Tetrahedron Lett., 1988, 29, 3049-3052.

90 L. Y. Shteinberg, S. A. Kondratov and S. M. Shein, Zh. Org. Khim., 1988, 24, 1968-1972.

91 S. A. Kondratov, L. Y. Shteinberg and S. M. Shein, Zh. Org. Khim., 1993, 29, 1914-1915.

92 L. Y. Shteinberg, S. A. Kondratov and S. M. Shein, Zh. Org. Khim., 1989, 25, 1945-1949.

93 L. Y. Shteinberg, S. A. Kondratov and S. M. Shein, Russ. J. Org. Chem., 2005, 41, 304-305.

94 L. Y. Shteinberg, S. A. Kondratov, S. M. Shein, S. E. Mishchenko, V. M. Dolmat and V. M. Dibrova, Kinet. Catal., 1999, 40, 511-515.

95 L. Y. Shteinberg, S. M. Shein and S. E. Mishchenko, Zh. Org. Khim., 1995, 31, 233-236.

96 L. Shteinberg, V. V. Marshalova, V. M. Dibrova and S. M. Shein, Russ. J. Gen. Chem., 2011, 81, 1839-1844.

97 L. Y. Shteinberg, S. A. Kondratov, S. M. Shein and V. V. Marshalova, Kinet. Catal., 2007, 48, 632-635.

98 A. C. Shekhar, A. R. Kumar, G. Sathaiah, V. L. Paul, M. Sridhar, P S. Rao, Tetrahedron Lett., 2009, 50, 7099-7101.

99 See the following article for mechanistic studies: D. Wei, C. Cui, Z. Qu, Y. Zhu, M. Tang, J. Mol. Struct. (Theochem), 2010, 951, 89-92.

100 N. Azizi, E. Gholibeglo, M. Babapour, H. Ghafuri, S. M. Bolourtchian, C. R. Chimie, 2012, 15, 768-773.

101 For a review on the topic of deep eutectic solvents, see: Q. Zhang, K D. O. Vigier, S. Royer, F. Jérôme, Chem. Soc. Rev., 2012, 41, 71087146.

102 H. Lundberg, F. Tinnis and H. Adolfsson, Synlett, 2012, 2201-2204.

103 Y. Terada, N. Leda, K. Komura and Y. Sugi, Synthesis, 2008, 23182320

104 G. Brahmachari, S. Laskar and S. Sarkar, Indian J. Chem., Sect B, 2010, 49, 1274-1281.

105 G. Brahmachari, S. Laskar and S. Sarkar, J. Chem. Res., 2010, 288295. 
106 V. M. de Oliveira, R. S. de Jesus, A. F. Gomes, F. C. Gozzo, A. P. Umpierre, P. A. Z. Suarez, J. C. Rubim and B. A. D. Neto, ChemCatChem, 2011, 3, 1911-1920.

107 K. Ishihara, Y. Kuroki, N. Hanaki, S. Ohara and H. Yamamoto, J. Am. Chem. Soc., 1996, 118, 1569-1570.

108 For reviews on the topic, see: (a) D. A. M. Zaia, Amino Acids, 2004, 27, 113-118. (b) A. Brack, Dev. Clay Sci., 2006, 1, 379-391. (c) T. A. E. Jakschitz and B. M. Rode, Chem. Soc. Rev., 2012, 41, 5484-5489

109 C. S. Reddy, A. Nagaraj and P. Jalapathi, Chin. Chem. Lett., 2007, 18, 1213-1217.

110 C. S. Reddy, M. Raghu and A. Nagaraj, Indian J. Chem., Sect B, 2008, 47, 315-318.

111 S. Gadhwal, M. P. Dutta, A. Boruah, D. Prajapati, J. S. Sandhu, Indian J. Chem., Sect. B, 1998, 37, 725-727.

112 N. Narender, P. Srinivasu, S. J. Kulkarni, K. V. Raghavan, Green Chem., 2000, 2, 104-105.

113 K. V. V. K. Mohan, N. Narender, S. J. Kulkarni, Green Chem., 2006, 8, 368-372.

114 S. Bahari, B. Mohammadi-Aghdam, S. M. Sajadi and F. Zeidali, Bull. Korean Chem. Soc., 2012, 33, 2251-2254.

115 A. Sakthivel, K. Komura, S. J. Huang, P. H. Wu, S. B. Liu, Y. Sasaki and Y. Sugi, Ind. Eng. Chem. Res., 2010, 49, 65-71.

116 M. Hosseini-Sarvari and H. Sharghi, J. Org. Chem., 2006, 71, 66526654.

117 H. Thakuria, B. M. Borah and G. Das, J. Mol. Catal. A: Chem., 2007, 274, 1-10.

118 F. Tamaddon, F. Aboee and A. Nasiri, Catal. Commun., 2011, 16, 194-197.

119 M. B. M. Reddy, S. Ashoka, G. T. Chandrappa and M. A. Pasha, Catal. Lett., 2010, 138, 82-87.

120 M. Hosseini-Sarvari, E. Sodagar and M. M. Doroodmandt, J. Org. Chem., 2011, 76, 2853-2859.

121 E. Safary, A. Jarrahpour, R. Heiran and M. Hosseini-Sarvari, C. $R$ Chimie, 2012, 15, 980-987.

122 B. Krishnakumar and M. Swaminathan, J. Mol. Catal. A: Chem., 2011, 334, 98-102.

123 S. Nagarajan, P. Ran, P. Shanmugavelan, M. Sathishkumar, A. Ponnuswamy, K. S. Nahm and G. G. Kumar, New J. Chem., 2012 , 36, 1312-1319.

124 V. K. Das, R. R. Devi, P. K. Raul and A. J. Thakur, Green Chem., 2012, 14, 847-854.

125 S. Ghosh, A. Bhaumik, J. Mondal, A. Mallik, S. S. Bandyopadhyay and C. Mukhopadhyay, Green Chem., 2012, 14, 3220-3229.

126 P. S. Chaudhari, S. D. Salim, R. V. Sawant and K. G. Akamanchi, Green Chem., 2010, 12, 1707-1710.

127 S. P. Pathare, R. V. Sawant and K. G. Akamanchi, Tetrahedron Lett., 2012, 53, 3259-3263.

128 B. M. Choudary, V. Bhaskar, M. L. Kantam, K. K. Rao, K. V. Raghavan, Catal. Lett., 2001, 74, 207-211.

129 K. V. N. S. Srinivas, B. Das, J. Org. Chem., 2003, 68, 1165-1167.

130 D. Mahanta and J. G. Handique, Lett. Org. Chem., 2011, 8, 618-324.

131 R. Arundhathi, M. A. Reddy, G. Parthasarathy and B. Sreedhar, Appl. Clay Sci., 2009, 43, 425-434.

132 L. Ma'mani, M. Sheykhan, A. Heydari, M. Faraji and Y. Yamini, Appl. Catal. A, 2010, 377, 64-69.

133 P. Kumar, R. K. Pandey, M. S. Bodas, S. P. Dagade, M. K. Dongare A. V. Ramaswamy, J. Mol. Catal. A: Chem., 2002, 181, 207-213.

134 J-G. Kim and D. O. Jang, Bull. Korean Chem. Soc., 2010, 31, 2989 2991.

135 J-G. Kim and D.O. Jang, Synlett, 2010, 1231-1234.

136 M. Hong and G. M. Xiao, J. Fluor. Chem., 2013, 146, 11-14.

137 D. Talukdar, L. Saikia and A. J. Thakur, Synlett, 2011, 1597-1601.

138 S. M. Coman, M. Florea, V. I. Parvulescu, V. David, A. Medvedovici, D. De Vos, P. A. Jacobs, G. Poncelet and P. Grange, J. Catal., 2007, 249, 359-369.
139 P. R. Likhar, R. Arundhathi, S. Ghosh and M. L. Kantam, , J. Mol. Catal. A: Chem., 2009, 302, 142-149.

140 L. Y. Shteinberg, V. D. Boiko, S. A. Kondratov, S. M. Shein and Y. B. Shteinberg, Zh. Org. Khim., 1992, 28, 1034-1038.

141 M. Kunishima, H. Imada, K. Kikuchi, K. Hioki, J. Nishida and S. Tani, Angew. Chem. Int. Ed., 2005, 44, 7254-7257.

142 M. Kunishima, K. Kikuchi, Y. Kawai and K. Hioki, Angew. Chem, Int. Ed., 2012, 51, 2080-2083.

143 M. Lei, L. Ma and L. H. Hu, Tetrahedron Lett., 2010, 51, 4186-4188.

144 G. Brahmachari and S. Laskar, Tetrahedron Lett., 2010, 51, 23192322.

145 S. Majumdar, J. De, J. Hossain and A. Basak, Tetrahedron Lett., 2013, 54, 262-266.

146 J.-G. Kim and D. O. Jang, Synlett, 2010, 2093-2096.

147 R. Luque, V. Budarin, J. H. Clark and D. J. Macquarrie, Green Chem., 2009, 11, 459-461.

148 J. W. Comerford, J. H. Clark*, D. J. Macquarrie and S. W. Breeden, Chem. Commun., 2009, 2562-2564.

149 J. W. Comerford, T. J. Farmer, D. J. Macquarrie, S. W. Breeden and J. H. Clark, ARKIVOC, 2012, 282-293.

150 K. Komura, Y. Nakano and M. Koketsu, Green Chem., 2011, 13, 828-831.

151 R. Malakooti, S. Sobhani, N. Razavi, S. Shafiei and R. Mokhtari, Collect. Czech. Chem. Commun., 2011, 76, 1979-1990.

152 M. R. M. Bhojegowd, A. Nizam and M. A. Pasha, Chin. J. Catal., 2010, 31, 518-520.

153 M. I. Ansari, M. K. Hussain, N. Yadav, P. K. Gupta and K. Hajela, Tetrahedron Lett., 2012, 53, 2063-2065.

154 (a) K. P. De Jong, Synthesis of solid catalysts, Wiley-VCH Verlag GmbH \& Co. KgaA, Weinheim, 2009.( b) M. Beller, A. Renken and R. Van Santen, Catalysis, Wiley-VCH Verlag GmbH \& Co. KgaA, 2012. (c) K. An and G. A. Somorjai, ChemCatChem, 2012, 4, 15121524

This journal is @ C The Royal Society of Chemistry [year]

Journal Name, [year], [vol], 00-00 | 29 